\title{
ELEVATION OF A FULL-THICKNESS MUCOPERIOSTEAL FLAP ALONE ACCELERATES ORTHODONTIC TOOTH MOVEMENT
}

\author{
A Thesis \\ by \\ KELLY MARTINEZ OWEN \\ Submitted to the Office of Graduate and Professional Studies of \\ Texas A\&M University \\ in partial fulfillment of the requirements for the degree of \\ MASTER OF SCIENCE
}

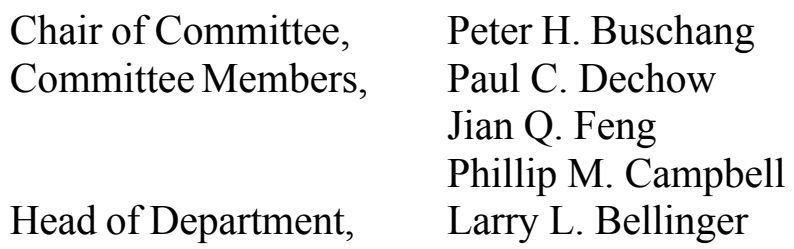

May 2015

Major Subject: Oral Biology

Copyright 2015 Kelly Martinez Owen 


\begin{abstract}
Introduction: The purpose of this study was to evaluate if elevation of a fullthickness mucoperiosteal flap alone decreases the amount of bone around teeth and accelerates mesial tooth movements. Methods: Seven beagle dogs were fitted with orthodontic appliances to protract the mandibular third premolars. Both mandibular second premolars were extracted. Then, using a randomized split-mouth design, one side of the mandible had a full-thickness mucoperiosteal flap elevated on the buccal aspect of the bone extending from the distal of the third premolar to the mesial of the first premolar; the other side of the mandible did not receive flap surgery. Tooth movements were analyzed over an eight-week period with calipers and radiographs. The amount and density of bone were analyzed using $\mu \mathrm{CT}$; bone remodeling was evaluated with histologic sections. Results: Experimental tooth movements measured intraorally were significantly greater $(25 \%)$ than control tooth movements $(3.86 \mathrm{~mm}$ versus $3.09 \mathrm{~mm})$. A similar $31 \%$ increase in tooth movement on the experimental side was seen radiographically. Medullary bone mesial to the third premolar showed a significantly lower $(8 \%)$ bone volume fraction and apparent density on the experimental side than on the control side. Histologic sections of the bone showed no distinct differences in the number of osteoclasts or osteoblasts when comparing the experimental and control medullary bone. Conclusions: Elevation of a full-thickness mucoperiosteal flap alone resulted in a decrease in medullary bone and accelerated tooth movement.
\end{abstract}




\section{DEDICATION}

This work is dedicated to my parents, Sean and Sylvia Martinez, and my husband, Joshua Owen, for their constant encouragement and support. 


\section{ACKNOWLEDGEMENTS}

I would like to thank my committee chair, Dr. Buschang, and my committee members, Dr. Campbell, Dr. Dechow, and Dr. Feng, for sharing their knowledge and providing their support throughout the course of this research. I would also like to thank Gerald Hill and Priscilla Hooks for their help and for their excellent care of the animals. For many hours of working together and brainstorming, I would like to thank my friend and classmate Britney Bare. And lastly, I would like to thank the rest of my classmates, John Feusier, Jason Morris, David White, and Brittany Wright, for their contributions to my education and always making me laugh. 


\section{TABLE OF CONTENTS}

Page

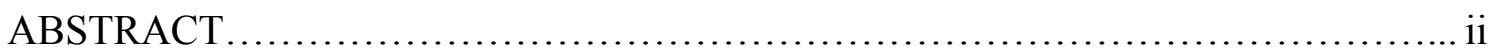

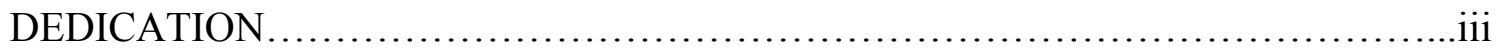

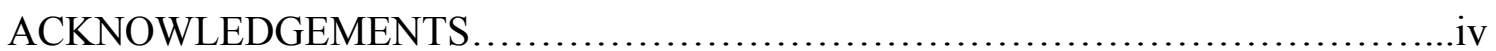

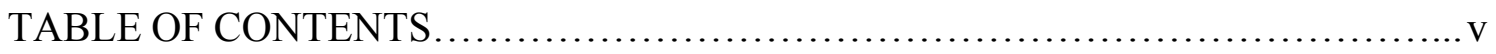

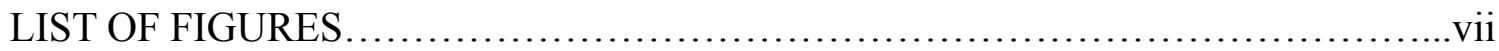

LIST OF TABLES................................................................. viii

CHAPTER

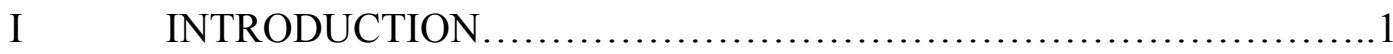

Tooth Movement Rates.........................................1

Biology of Tooth Movement..................................8

Effect of Bone Remodeling Rates and Density on Tooth

Movement................................................. 10

Regional Acceleratory Phenomenon........................ 12

Periosteal Flaps and the RAP ..............................20

II PURPOSE AND SIGNIFICANCE ............................... 24

III MATERIALS AND METHODS ................................. 26

Pre-Surgical Preparation.......................................26

Appliance Design..........................................27

Surgical Protocol and Appliance Placement........................28

Measurements and Appliance Activation.......................29

Euthanasia.................................................29

Radiographic Analysis of Movement.......................... 29

MicroCT Assessment of Bone Density........................ 30

Histologic Evaluation of Specimens............................32

Statistical Analyses.......................................... 32

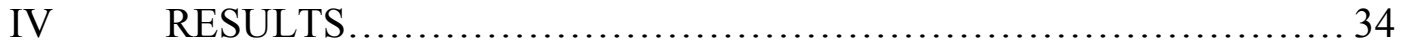


Clinical Implications....................................... 39

VI CONCLUSIONS..........................................41

REFERENCES............................................................ 42

APPENDIX A FIGURES ................................................ 50

APPENDIX B TABLES.................................................... 56 


\section{LIST OF FIGURES}

Page

Figure $1 \quad$ Standardized radiographic holder................................50

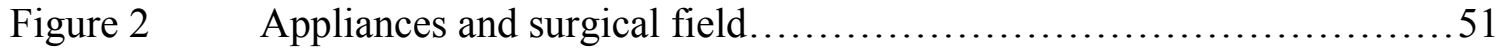

Figure 3 Radiographic landmarks and measurements......................52

Figure 4 Cumulative tooth movements measured intraorally..................53

Figure 5 Radiographic measurement of tooth movement and tipping.............54

Figure 6 Area of medullary bone mesial to the third premolar assessed by microCT ........................................................55 


\section{LIST OF TABLES}

Page

Table $1 \quad$ Incidences of damaged appliances..............................56

Table 2 Multilevel comparisons of control side tooth movement and differences to experimental side tooth movement with linear and quadratic estimates...........................................57

Table 3 Bone volume ratios and bone densities for medullary bone mesial to the third premolar................................................ 58 


\section{CHAPTER I}

\section{INTRODUCTION}

According to the American Association of Orthodontists, the length of comprehensive orthodontic treatment "can range from one to three years." Studies on treatment time have found durations ranging from 21-27 months for nonextraction treatment and 25-35 months for extraction treatment. ${ }^{1-7}$ Treatment times are influenced by many factors including type of malocclusion, amount of tooth movement required, mechanics utilized, and patient compliance. ${ }^{2,8,9}$

With prolonged orthodontic treatment time comes increased risk of root resorption, ${ }^{10,11}$ decalcification, ${ }^{12}$ and periodontal problems. ${ }^{13}$ In an effort to minimize these risks, orthodontists are continually trying to reduce treatment time while providing treatment results equal to or better than those currently being delivered.

One way to reduce treatment time in orthodontic patients is to increase the rate of tooth movement. The rate of tooth movement will be discussed as well as the biology of tooth movement and different ways in which tooth movement can be accelerated.

\section{Tooth Movement Rates}

One of the main determinants of orthodontic treatment time is the rate of tooth movement that can be achieved. Much research has been done to quantify the rate of tooth movement possible, with most studies showing approximately $1 \mathrm{~mm}$ of tooth movement per month. ${ }^{14-18}$ 


\section{Clinical Studies}

One factor that has long been believed to affect rate of tooth movement is the amount of force applied to teeth. Boester and Johnston ${ }^{14}$ conducted a split-mouth study comparing space closure rates while retracting canines using retraction springs of $2,5,8$, and $11 \mathrm{oz}$ of force (approximately 55, 140, 225, and $310 \mathrm{~g}$ of force). Springs were reactivated weekly for ten weeks. The 2-ounce force group showed significantly slower tooth movement. However, the results showed that space closure occurred at the same rate for forces from 5-11 ounces. Boester and Johnston suggested that within this force range, bone resorption may be occurring at a maximal rate and thus be the rate-limiting factor.

Samuels et al $^{15}$ compared the effect of using continuous versus intermittent forces during space closure after premolar extraction. They compared continuous light forces from $150 \mathrm{~g}$ nickel-titanium (NiTi) closing coils to heavy intermittent forces from elastomeric ligation that started at 400 to $450 \mathrm{~g}$. Patients had the two quadrants of each arch used in the study randomized to receive one quadrant with each space closure method. The results showed an average space closure of $0.19 \mathrm{~mm}$ per week using elastomeric ligation while closing coils provided significantly faster average space closure of $0.26 \mathrm{~mm}$ per week. In a follow-up study by Samuels et al ${ }^{16}$ comparing $100 \mathrm{~g}$ NiTi closing coils to $200 \mathrm{~g}$ NiTi closing coils it was found that the $100 \mathrm{~g}$ springs closed space at a rate of $0.16 \mathrm{~mm}$ per week and the $200 \mathrm{~g}$ springs closed space at a rate of 0.24 mm per week. When they combined the results of both of their studies, Samuels et al concluded that there was no significant difference in the rates of space closure caused by 
$150 \mathrm{~g}$ and $200 \mathrm{~g}$ springs but that $150 \mathrm{~g}$ and $200 \mathrm{~g}$ springs did produce faster rates of space closure compared to the elastic module or the $100 \mathrm{~g}$ spring.

In a study using lower force magnitudes, Iwasaki et $\mathrm{al}^{17}$ retracted maxillary canines in a split-mouth design by applying $18 \mathrm{~g}$ of force on one canine and $60 \mathrm{~g}$ on the other canine. Their appliance used closing loops activated with NiTi closed coil springs. They also employed anchorage consisting of a Nance or Nance/TPA to the first molars and coligation of the second premolars through second molars bilaterally in an effort to maximize pure canine retraction. Their results showed a significant difference in space closure rates between the groups; the $60 \mathrm{~g}$ force produced tooth movement of $1.27 \mathrm{~mm}$ per month whereas the $18 \mathrm{~g}$ force produced tooth movement of $0.87 \mathrm{~mm}$ per month. However, the authors noted that the main difference in tooth velocity between the two groups was due to the larger amount of tooth movement that occurred in the higher force group in the first three days of the study and that after exclusion of the first three days, velocities were not significantly different.

Mathematical models of tooth movement by Ren et a ${ }^{19}$ were developed to determine the force level that might provide the maximum velocity of tooth movement. Using data from four beagle dog studies and nine human studies, models for tooth movement in both humans and dogs were developed. For the human mathematical model they found that a force of $272 \mathrm{cN}(277 \mathrm{~g})$ produced a mean maximum velocity of canine retraction of $0.29 \mathrm{~mm} / \mathrm{wk}$. They concluded that the maximum rate of tooth movement in humans is not significantly different across a wide range of force levels that can potentially elicit the same optimum tooth movement. 
Another factor that possibly influences the rate of tooth movement is mode of force application. Nightingale and Jones ${ }^{18}$ conducted a split-mouth study of canine retraction rates comparing the use of elastomeric chain and NiTi coil springs. Elastomeric chains delivered initial forces from 70-450 g (mean of $209 \mathrm{~g}$ ) and coil springs delivered initial forces from 150-460 g (mean of $300 \mathrm{~g}$ ). Space closure with elastomeric chains occurred at a rate of $0.21 \mathrm{~mm}$ per week while space closure with coil springs occurred at $0.26 \mathrm{~mm}$ per week. The results indicated no statistically significant difference in canine retraction rate between the two modes of force application.

Application of force in an intermittent versus a continuous fashion has also been studied. Daskalogiannakis and McLachlan ${ }^{20}$ studied space closure rates in a split-mouth design study of canine retraction. On the control side, a TMA vertical retraction loop delivered an intermittent force of $70 \mathrm{~g}$ and was reactivated every six weeks. The experimental side consisted of the same closing loop activated with a continuous force of approximately $60 \mathrm{~g}$ using rare earth block magnets. The rate of movement on the control side was $0.63 \mathrm{~mm}$ over four weeks, while the experimental side showed a significantly greater rate of tooth movement at $1.22 \mathrm{~mm}$ over four weeks, indicating a greater rate of tooth movement with continuous force application.

Effects of sliding mechanics can be influenced by friction and binding between brackets and archwires. In a study to assess the relative role of friction and binding, Burrow $^{21}$ conducted a split-mouth study between self-ligating brackets (Damon3 and SmartClip) and conventional twin brackets (Victory Series) in canine retraction. All teeth were bonded with Victory Series brackets except for the experimental canine, a 
TPA was placed, and canines were retracted on a 0.018-inch stainless steel archwire with $150 \mathrm{~g}$ NiTi retraction springs. Over a four-week period, tooth movement with the conventional bracket was $1.17 \mathrm{~mm}$. Rates for self-ligating brackets were $0.9 \mathrm{~mm}$ (Damon3) and $1.10 \mathrm{~mm}$ (SmartClip) over four weeks. The differences in rate between conventional and self-ligating brackets were statistically significant. The authors concluded that although self-ligating brackets would have theoretically provided less friction to sliding and therefore should have given a faster rate of tooth movement, the geometry of the brackets might have played a role. The self-ligating brackets had a narrower width and as such there may have been higher binding of the self-ligating brackets with the archwires.

Other studies into the relationship between ligation and rate of tooth movement have shown no difference. Scott et $\mathrm{al}^{22}$ showed no difference in efficiency of initial alignment in a randomized controlled trial between patients with self-ligating brackets

versus conventional brackets. Similarly, da Costa Monini et $\mathrm{al}^{23}$ found no difference in rate of canine retraction between conventional and self-ligating appliances in a splitmouth design experiment.

Experimental Studies

Research performed in the dog model has aided in our understanding of tooth movement rates due to the ability to have highly controlled randomized trial environments. The dog model is particularly useful for studying tooth movement due to similar characteristics between the alveolar bone in dogs as compared to humans. ${ }^{24,25}$ Pilon et $\mathrm{al}^{26}$ studied rates of distalization of mandibular second premolars in a split- 
mouth study using forces of 50, 100, and $200 \mathrm{~g}$ from prestretched elastic modules. From time-displacement curves, the authors discriminated four phases: the initial tooth movement phase, the arrest of tooth movement phase, the acceleration of tooth movement phase, and the constant linear tooth movement phase. Their results showed no significant difference in tooth movement rates during any of these phases or differences in the lengths of these phases between force level groups. This indicates that tooth movement rate was independent of force applied at the levels tested $(50,100$, and 200 g). They reported large individual differences in rate of tooth movement between dogs, however left and right sides of each dog were highly correlated. The maximum rate of tooth movement found in any group was $2.5 \mathrm{~mm}$ per month.

As mentioned previously, Ren et $\mathrm{al}^{19}$ developed mathematical models to describe the relationship between rate of orthodontic tooth movement and force magnitude applied. These mathematical models demonstrated that for the beagle dog, a force of 248 $\mathrm{cN}(253 \mathrm{~g})$ produced a mean maximum velocity of the mandibular second premolar of $0.27 \mathrm{~mm} / \mathrm{wk}$. The optimum force magnitude derived from their equation suggested a substantial range of 104-454 $\mathrm{cN}$ (106-463 g), indicating that force magnitude is not the major decisive factor for the rate of tooth movement. Instead, any force within the reported range may elicit the necessary biologic response for optimal tooth movement. These findings were similar to what they found in their human mathematical model.

Owens et $\mathrm{al}^{27}$ evaluated orthodontic tooth movement using miniscrew implants (MSIs) for skeletal anchorage. Mandibular third premolars were extracted and an MSI was placed mesial to the fourth premolars. The second premolars were distalized using 
either 25 or $50 \mathrm{~g}$ NiTi coil springs against the MSIs. Results of the 105-day experiment showed no difference in tooth movement between the two force levels with a mean overall rate of $36 \mu \mathrm{m} /$ day in the mandible $(0.25 \mathrm{~mm} / \mathrm{wk})$.

Carrillo et $\mathrm{al}^{28}$ performed a split-mouth study in eight beagle dogs assessing the effect of varying force levels on intrusion of teeth. In the study, MSIs were placed in the mandible to allow for intrusion of second, third, and fourth mandibular premolars each independently, using forces of $50 \mathrm{~g}, 100 \mathrm{~g}$, or $200 \mathrm{~g}$ delivered by NiTi coil springs. They found no significant difference in amount of premolar intrusion achieved among the different force groups.

Continuity of force application can also affect rate of tooth movement. Van Leeuwen et al ${ }^{29}$ evaluated tooth movement using light continuous and discontinuous forces in beagle dogs. Mandibular third premolars were extracted and mandibular second premolars distalized. The distalizing force from the orthodontic appliance was applied with NiTi coil springs with either 10 or $25 \mathrm{cN}$ (10.2 or $25.5 \mathrm{~g}$ ) of force and left in place either continuously or 16 hours per day. Similar to Pilon et al, ${ }^{26}$ they categorized the tooth movements as occurring through four phases (initiation, arrest, acceleration, and linear) throughout the 120-day experiment. When studying the linear portion of timedisplacement curves they found that the continuous force group had the highest rates of tooth movement: $52.4 \mu \mathrm{m} / \mathrm{day}(0.367 \mathrm{~mm} / \mathrm{week})$ for the $25 \mathrm{cN}$ group and $46.3 \mu \mathrm{m} / \mathrm{day}$ $(0.324 \mathrm{~mm} /$ week) for the $10 \mathrm{cN}$ group. The discontinuous force group had a slower rate of tooth movement with $35.8 \mu \mathrm{m} /$ day $(0.251 \mathrm{~mm} / \mathrm{week})$ for the $25 \mathrm{cN}$ group and 30.0 $\mu \mathrm{m} /$ day $(0.210 \mathrm{~mm} /$ week $)$ for the $10 \mathrm{cN}$ group. They also showed a significant 
difference in the duration of the "arrest phase," with that phase lasting longer in the continuous force group rather than the discontinuous force group, which may be indicative of more hyalinization occurring during the application of continuous force.

\section{Biology of Tooth Movement}

There are many proposed mechanisms to explain bone remodeling and tooth movement. These include the piezoelectric, mechanotransduction, and pressure-tension theories among others. These hypotheses differ in their explanation of tooth movement and it is possible that the actual method of tooth movement may be an amalgamation of multiple ideas.

Piezoelectric Hypothesis

When an applied force deforms bone, a change in electric polarity along the surface of the bone occurs. This phenomenon is termed the piezoelectric effect and can be seen in many crystalline structures. ${ }^{30,31}$ Bassett and Becker ${ }^{32}$ in the early 1960s found that the crystalline structures in bone under mechanical stress respond to deformation by emitting electrical potentials that can stimulate bone formation. During tooth movement, there is a net movement of positively charged ions to the pressure side and negatively charged ions to the tension side. This may be thought to play a role in signaling tooth movement. The phenomenon is brief, and upon removal of the force the equivalent signals are generated in the opposite direction. ${ }^{30}$ It has also been shown that teeth move more quickly with application of electric current and force than with force alone. ${ }^{31}$ In a study by Davidovitch et $\mathrm{al}^{31}$ using the cat model, teeth that received force plus electric current application moved significantly more than teeth that received force alone. Upon 
examination of the tissues after sacrifice they found that there was greater bone resorption present in the electric current with force side compared to the force alone side. This was consistent with bone resorption seen at the anode and deposition seen at the cathode in their previous research on the effect of electric current on bone. ${ }^{33}$ Mechanotransduction Hypothesis

The possibility of electrical currents stimulating bone remodeling might better be explained by the mechanotransduction hypothesis. The mechanical energy of orthodontic force is thought to be converted into an electrical and/or biochemical signal by osteocytes in the bone. ${ }^{34}$ It is thought that the signals for bone remodeling are relayed through the network of canaliculi and gap junctions in bone, in what is referred to as the osseous connected cellular network. ${ }^{35,36}$

\section{Pressure-Tension Hypothesis}

In the early $20^{\text {th }}$ century, research by Sandstedt, ${ }^{37}$ Oppenheim, ${ }^{38}$ and Schwarz ${ }^{39}$ led to development of the pressure-tension theory. This theory is based on the idea that movement of the tooth leads to stretching and compression of the periodontal ligament (PDL). Histologically it can be seen that there is bone deposition on the alveolar wall on the tension side and bone resorption on the pressure side as well as a narrower PDL space on the pressure side. Under light pressure, osteoclasts are able to perform frontal resorption with removal of bone immediately adjacent to the PDL that is under compression. Under high pressures, however, the development of a cell-free necrotic zone of "hyalinization" is seen. Osteoclasts must then invade from undamaged 
medullary bone toward the site of hyalinization in a process known as undermining resorption. ${ }^{40,41}$

Tooth movement within the alveolar process requires bone turnover, with bone resorption occurring at the sites into which teeth are being moved, and bone formation occurring in sites from which teeth are being moved away. King et $\mathrm{al}^{42}$ analyzed histologic sections of alveolar bone adjacent to molars moved orthodontically in rats. They found that in orthodontically moved teeth, bone resorption was found primarily on the "pressure" side by measuring resorption perimeter, and bone formation was shown primarily on the "tension" side by measuring osteoblast perimeter.

\section{Effect of Bone Remodeling Rates and Density on Tooth Movement}

There is a relationship between rates of tooth movement and rates of bone remodeling. Verna et al used 52 Wistar rats divided into three groups: control, high bone turnover, and low bone turnover. ${ }^{43}$ The high and low turnover groups were pharmacologically induced by changes in thyroid function for four weeks prior to application of orthodontic force. A constant mesial force was applied to the maxillary first molar for three weeks and rates of tooth movement were recorded. They found that there was a higher rate of tooth movement in the high bone turnover group and a reduced rate of tooth movement in the low bone turnover group compared to the control group.

Bone density itself also affects the rate of tooth movement, with faster tooth movement occurring in less dense bone and slower movement in more dense bone. This was confirmed by Goldie et $\mathrm{al}^{44}$ in a study utilizing calcium-deficient rats. Thirty-five adult female rats were divided into two groups: a control group and a calcium-deficient, 
lactating group. Maxillary molars were moved mesially by an orthodontic force and tooth movement was evaluated. They found that animals with decreased bone density had a significant increase in tooth movement. It was concluded that the accelerated tooth movement was correlated to the decreased bone density in the calcium-deficient rats.

A similar study by Ashcraft et al, ${ }^{45}$ assessed the effects of osteoporosis on tooth movement. Using sixteen New Zealand white rabbits, experimental rabbits received cortisone acetate to induce osteoporosis while control rabbits received no such pharmacologic intervention. The maxillary left first molars were mesialized orthodontically and tooth movement was evaluated. They found that rabbits with corticosteroid-induced osteoporosis exhibited a three- to four-fold increase in the rate of tooth movement compared to controls.

Collins and Sinclair ${ }^{46}$ studied the effect of localized injections of 1,25dihydroxycholecalciferol (active vitamin D), a stimulator of osteoclastic activity, on the rate of tooth movement. Using five cats in a split-mouth design, either vitamin D dissolved in dimethylsulfoxide or dimethylsulfoxide alone was injected into the PDL on the distal of the experimental canines. The canines were retracted orthodontically using an $80 \mathrm{~g}$ force. After 21 days, the experimental teeth had moved $60 \%$ further than the control teeth. Histologically, they showed an increase in osteoclasts at experimental sites, consistent with the role of vitamin D as a stimulator of osteoclast activity.

Kobayashi et al ${ }^{47}$ studied the effect of local administration of osteocalcin, a bone matrix protein involved in recruitment and differentiation of osteoclasts, on the rate of tooth movement in rats. They found a significant increase in the rate of tooth movement 
and number of osteoclasts present after local administration of osteocalcin in rats compared to controls that only received administration of phosphate-buffered saline (PBS). Yamasaki et $\mathrm{al}^{48,49}$ similarly showed an increase in the rate of tooth movement after local administration of prostaglandin E1, a biochemical mediator of bone resorption in both monkeys and humans.

In an experiment to prevent bone turnover by decreasing osteoclastic activity, Ortega et al ${ }^{50}$ evaluated the effects of local administration of the bisphosphonate zoledronate. Using thirty rats, maxillary first molars were extracted and maxillary second molars were orthodontically protracted. Control rats received local injections of PBS and experimental rats received local injections of zoledronate. They found that control rats showed significant tooth movement, whereas experimental rats showed no tooth movement after the first week of the experiment.

\section{Regional Acceleratory Phenomenon}

Another way to increase bone remodeling rates and decrease bone density is

through the regional acceleratory phenomenon (RAP). Coined by Frost, ${ }^{51-53}$ the RAP is a sequence of tissue reactions during healing of injured bone. Frost described the RAP as a "complex reaction of mammalian tissues to diverse noxious stimuli...[it] occurs regionally in the anatomical sense, involves both hard and soft tissues, and is characterized by an acceleration and domination of most ongoing normal vital tissue processes." Noxious stimuli he identified include crushing injuries, fractures, and bone operations, to name a few. Since then it has also been shown that even orthodontic forces can stimulate the RAP. ${ }^{54}$ 
The response of the RAP is an acceleration of normal hard and soft tissue processes that are associated with healing; these processes include increased bone turnover and modeling, cellular metabolism, and growth of hard and soft tissues. Frost reported that from a single stimulus/injury, the RAP occurs for approximately four months in bone. ${ }^{51}$ In bone, the RAP causes a temporary increase in bone remodeling and decrease in regional bone density. This decrease in regional bone density might be expected to produce faster tooth movement during orthodontic treatment.

\section{Corticotomies}

Corticotomies, surgical cuts made into the cortex of the alveolar bone, have been used to enhance the rate of orthodontic tooth movement dating back to Kole in $1959 .{ }^{55-57}$ The procedure was originally believed to enhance the rate of tooth movement through displacement of bony segments. ${ }^{55-59}$ It was not until 2001 that the Wilcko brothers associated the faster tooth movement produced with corticotomies with the RAP rather than block bone movement. ${ }^{60}$ In their original protocol, orthodontic appliances are placed, full-thickness mucoperiosteal flaps are elevated from a coronal approach, and vertical corticotomies are made between the teeth extending from 2-3 mm apical of the alveolar crest to $2 \mathrm{~mm}$ beyond the tooth apices and connected by a scalloped subapical corticotomy; this process is done on both the labial and lingual aspects. In cases where the bone is at least $2 \mathrm{~mm}$ thick over the roots, perforations are also made in the cortical bone in a stippling pattern. After all cuts have been completed, bone allograft is applied and the tissues are reapproximated. Using this protocol they have reported cases with 
treatment times as short as six months. Although the Wilcko brothers report faster tooth movement, their conclusions are drawn from case studies without controls. ${ }^{60-62}$

A randomized clinical trial that assessed the effect of corticotomy on tooth movement was performed by Fischer in $2007 .{ }^{63}$ It pertained to six consecutive patients with bilateral palatally impacted canines. A split-mouth design was utilized in which one side had a traditional canine exposure and the other side had the canine exposed with cortical perforations made to the mesial and distal of the canine; both canines were then retracted orthodontically. The canines with corticotomies showed a $28-33 \%$ reduction in treatment time, with no difference in final periodontal status.

Another clinical trial by Lee et $\mathrm{al}^{64}$ studied a sample of 65 Korean adult female patients. The patients were randomly assigned by the clinician to three groups: no treatment $(n=29)$, maxillary corticotomy assisted orthodontics with skeletal anchorage and mandibular anterior segmental osteotomy $(n=20)$, or maxillary and mandibular anterior segmental osteotomy $(n=16)$. The authors noted greater upper lip change in the corticotomy group compared to controls as well as a shortened treatment time. However, the three groups were not equivalent prior to treatment and randomization of treatment assignment was unclear.

Better able to control confounding variables, several animal studies have been performed to evaluate the effects of corticotomies. In 2007, Cho et al ${ }^{65}$ conducted a splitmouth study in two beagle dogs. The second premolars were extracted and allowed to heal for four weeks prior to the experiment. Full-thickness mucoperiosteal flaps were then elevated and cortical perforations were created in the buccal and lingual cortical 
plates in the areas of the maxillary and mandibular third premolars on the experimental side. A $150 \mathrm{~g}$ force was then applied with a NiTi closing coil to protract the third premolars. At the end of eight weeks, experimental teeth had moved approximately four times further than control teeth in the maxilla $(6.4 \mathrm{vs.} 1.5 \mathrm{~mm})$ and two times further in the mandible (3.3 vs. $1.4 \mathrm{~mm}$ ). They also showed that it was approximately at two weeks when the velocity of the experimental teeth increased versus the control teeth. However, small sample size limited the results of this study.

Using twelve dogs, Iino et al ${ }^{66}$ extracted mandibular second premolars and protracted mandibular third premolars. On their experimental side, a full-thickness mucoperiosteal flap was elevated on the buccal and lingual areas over the third premolar. On both the buccal and lingual, vertical corticotomies were made mesial and distal to the third premolar and connected by a horizontal subapical corticotomy. The flaps were then reapproximated and $0.5 \mathrm{~N}$ of protractive force was applied with a NiTi closed coil spring. They found that velocity of tooth movement was significantly increased on the side with corticotomies compared to the control side during the first two weeks of the experiment. Velocity of tooth movement during the first week was approximately two times faster in the experimental group. During the second week, the experimental group had a tooth movement velocity approximately five times faster than the control. By the end of the four-week experiment, they found that experimental teeth had moved approximately twice the distance as control teeth.

Sanjideh et $\mathrm{a}^{67}$ studied tooth movement in foxhound dogs after one or two corticotomy procedures. In their study, mandibular third and maxillary second premolars 
were extracted on the same day as corticotomy procedures. One mandibular quadrant had buccal and lingual flaps and corticotomies performed around the second premolar. In the maxilla, both quadrants had buccal flaps and corticotomies performed around the third premolars. After four weeks, a second corticotomy procedure was performed in one maxillary quadrant. Beginning after the first surgery, coil springs of $200 \mathrm{~g}$ force were used to retract the mandibular second premolars and protract the maxillary third premolars. Tooth movement rates appeared to peak at 22 days in the mandible and at 25 days in the maxilla. After eight weeks, mandibular tooth movement was significantly greater on the experimental side than on the control side $(2.4 \mathrm{~mm}$ and $1.3 \mathrm{~mm}$ respectively). In the maxilla, there was significantly more overall tooth movement on the side that had two corticotomies $(2.3 \mathrm{~mm})$ versus the side that had one corticotomy procedure $(2.0 \mathrm{~mm})$, albeit the difference was small. They concluded that the corticotomy procedure significantly increased orthodontic tooth movement and that performing a second corticotomy procedure can produce an additional boost in tooth movement, but that the effect from the second corticotomy was substantially less and could not be clinically recommended.

In a study to examine the effects of increased surgical trauma on the rates of tooth movement, Cohen et $\mathrm{al}^{68}$ and $\mathrm{McBride}$ et $\mathrm{al}^{69}$ performed a randomized split-mouth study in foxhound dogs. On one side of the maxilla, the first premolar was extracted and interseptal bone mesial to the second premolar was undermined (designated the RAP side). On the other side, designated RAP+, the first premolar was extracted, a fullthickness flap was elevated, and the buccal plate between the canine and second 
premolar was removed; a vertical osteotomy extending to the lingual cortex was then made distal to the second premolar. They found that the RAP+ side experienced a significant increase of $62 \%$ in tooth movement due to the increased nature of the surgical trauma. They also showed that the RAP+ side had significantly less material density and bone volume fractions in select regions compared to the RAP side and that the RAP+ side had significantly more trabeculae that were thinner and with less trabecular separation compared to both the RAP side and control bone.

\section{Flapless Corticotomies}

In an effort to reduce the surgery required during the corticotomy procedure, recent research has focused on performing so-called flapless corticotomies to produce the RAP and accelerate tooth movement.

In a study by Safavi et al, ${ }^{70}$ five dogs were used to study the effect of flapless bur decortications on tooth movement. Maxillary first premolars were extracted on the day of surgery and using a split-mouth design, one side of the arch had small holes drilled through the attached gingiva and into the buccal cortical table. On each experimental side, 25 holes $2 \mathrm{~mm}$ deep were created using a surgical handpiece. The holes were placed on the experimental side mesial and distal to the second premolar and on the buccal cortical table of the extracted tooth. On both sides of the maxilla, a $150 \mathrm{~g}$ force was applied to protract the second premolars with NiTi coil springs. They repeated the decortications at the end of the first month and at the end of the second month. They found that during the first month, the second premolars on the decortication side moved $0.82 \mathrm{~mm}$ more than on the control side, which was statistically significant. However, 
during the second month the difference was small (only $0.04 \mathrm{~mm}$ ) and not significant. During the third month, the control side moved significantly further than the experimental side by $1.15 \mathrm{~mm}$. The difference between total amounts of tooth movement on the two sides after three months was not statistically significant.

Kim et $\mathrm{al}^{71,72}$ studied the effects of corticision and low-level laser therapy (LLLT) on tooth movement. The corticision procedure used a reinforced surgical blade and mallet to penetrate through gingiva and into alveolar bone. In this study, twelve dogs were divided into four groups of three dogs each. Only the corticision and control groups pertain to this review. In the corticision group, corticision was performed on the mesiobuccal, distobuccal, mesiopalatal, and distopalatal sides of the maxillary second premolar. The blade used penetrated $10 \mathrm{~mm}$ through the gingiva and into cortical and medullary bone. Maxillary second premolars were then protracted with NiTi springs of $150 \mathrm{~g}$ for eight weeks. They showed that the corticision group moved 3.75 times more than the control group. However, it is important to emphasize that their injuries penetrated much further than traditional corticotomy.

One tool currently on the market for performing micro-osteoperforations is the Propel system. In a recent study by Alikhani et al, ${ }^{73}$ twenty adults with Class II Division 1 malocclusions requiring premolar extractions were randomly divided into control and experimental groups. After extraction of teeth, orthodontic leveling and aligning was performed. Once canine retraction was ready to begin, the experimental group received micro-osteoperforations using the Propel device on one side of the maxilla. The device was set to deliver perforations $1.5 \mathrm{~mm}$ wide and 2-3 $\mathrm{mm}$ deep. Three perforations were 
made distal to the canine on the experimental side. Retraction of canines was then performed, using a $100 \mathrm{~g}$ NiTi coil spring that extended from the canine to a MSI placed mesial to the first molar. The authors reported a 2.3 -fold increase in the rate of tooth movement on the experimental side, which was statistically significant $(\mathrm{p}<0.05)$. They also measured cytokine and chemokine levels from the gingival crevicular fluid of the patients 24-hours after canine retraction was initiated. While there was a trend for the experimental group to have elevated levels of these inflammatory markers, there was no statistically significant difference between experimental and control groups.

Again, animal based experiments must be performed in order to better elucidate the bone reaction to microfractures. In a split-mouth experiment performed by Swapp et $\mathrm{al},{ }^{74}$ the effects of bone-awl induced injuries (puncture holes and microfracture of surrounding bone) on tooth movement were evaluated using seven foxhound dogs. Mandibular second premolars were extracted on both sides of the arch and a bone awl was used on the experimental side to create 60 bone injuries on the buccal and lingual cortical plates. Using $5 \mathrm{~mm}$ and $6 \mathrm{~mm}$ bone awls, a grid of injury sites was created over the area of the roots of the mandibular third premolar, as well as $5-6 \mathrm{~mm}$ mesial to the tooth both on the buccal and lingual cortical plates. The mandibular third premolar was then mesialized against the mandibular canine with a $200 \mathrm{~g}$ NiTi coil spring. No difference was found in the rate of tooth movement between experimental and control sides. MicroCT showed differences in the cortical bone, but not the medullary bone through which the teeth were moved. Tooth movements were the same because medullary bone volume fraction and bone density on the experimental and control side 
were the same. The experimental side showed significant cortical bone remodeling in the area of injury while the control side demonstrated almost no remodeling. In other words, the RAP was limited to the cortex.

\section{Periosteal Flaps and the RAP}

According to Frost, ${ }^{51-53}$ the RAP involves the region where injury occurs and the transition between involved and uninvolved regions of the bone is gradual. He also reported "the distribution of the RAP seems to reflect regional vascular anatomy and innervation." Regional vascularization of the bone comes from two sources, medullary bone and periosteum. However, corticotomy studies have failed to control for potential RAP effects due to the periosteal flap elevated during the corticotomy procedure.

It is known that periosteal resection causes significant changes in blood supply to cortical bone. Histophysiology studies have shown that periosteal blood circulation to the bone cortex provides up to $70-80 \%$ of arterial supply and $90-100 \%$ of venous return in animal long bones. ${ }^{75}$ While not specific to the alveolus and the maxillary-mandibular complex, it seems plausible that the mandible (which is similar in its vascular network to long bones) may show a similar pattern of blood flow to cortical bone.

Some of the early experiments on the RAP focused on stripping of the periosteum as a stimulus for the RAP in flat bones. These experiments, performed by High et al, ${ }^{76-78}$ used the canine model to assess the effects on bone remodeling due to various hormones as well as periosteal elevation on ribs. They found that regardless of the hormones administered, ribs with periosteal stripping showed significantly accelerated turnover of cortical bone compared to uninjured ribs in a 60-day timeframe. 
In a 1994 study by Yaffe et al, ${ }^{79}$ the RAP was shown to be produced by elevation of a full-thickness mucoperiosteal flap in the mandible of rats. In the study, $60 \mathrm{Wistar}$ rats were divided into three groups: a control group, a full-thickness mucoperiosteal buccal flap group, and a full-thickness mucoperiosteal buccal and lingual flap group. Flap surgeries were done by elevation with a special periosteal elevator and readapted without sutures. Rats were sacrificed at 7, 10, 14, 17, 21, and 120 days post-surgically to assess sections of the alveolus. Resorption of alveolar bone was seen as early as 10 days in rats with flap elevation, with more extensive resorption in rats that had both buccal and lingual flaps elevated. Maximum resorption was seen three weeks after surgery and bone volume appeared to return to almost control levels 120 days after surgery.

A later study by Binderman et $\mathrm{al}^{80}$ showed that local remodeling of bone is greater when the flap is from a coronal approach rather than from an apical approach. They divided 18 Wistar rats into two groups: one group had mucoperiosteal flap surgery using a coronal approach and the other group had surgery using an apical approach. Each group had buccal and lingual flaps from the appropriately designated approach done on one side of the mandible, with the other side of the mandible serving as an unoperated control. The rats were sacrificed after 21 days. In the coronal flap group there was extensive resorption of the periodontal aspect of the alveolar bone. Alveolar crestal bone had empty osteocyte lacunae and many osteoclasts were seen on the inner surface of alveolar bone. Based on histologic sections, $46 \%$ of the coronal approach group showed mild to severe vertical alveolar bone loss. In the apical flap group there was only slight resorption at the level of the mucosal incision, with some modeling of new trabecular 
bone coronal to the incision. Newly formed bone was on the alveolar bone surface, with an abundance of osteoblasts and osteocytes. Approximately $13 \%$ of the sections from the group using an apical approach showed mild vertical alveolar bone loss, which was significantly less than the bone loss seen in the coronal flap approach group. The authors suggested that the increased vertical alveolar bone loss in the coronal flap group might have been due to the injury of the marginal gingival connective tissue. While this provides an explanation for the differences between the coronal and apical flap groups, it does not explain the qualitative changes to the alveolar bone seen in the apical flap group.

In a split-mouth study comparing full-thickness and partial-thickness flap elevation, Fickl et $\mathrm{al}^{81}$ showed greater vertical bone loss occurs after elevation of a fullthickness flap than after elevation of a partial-thickness flap on the buccal aspect of the dog mandible. However, this study only used five beagle dogs, one of which was excluded because it showed results opposite to the other four dogs. The authors did note that in all of the surgical flap areas, resorption was evident on the buccal aspect of the alveolar bone indicating high osteoclastic activity.

A recent study by Young et $\mathrm{al}^{82}$ compared 13 rats that had fiberotomies performed around the maxillary molars, 14 that had apical mucoperiosteal flaps elevated, and 7 that had no surgery. The right side had an appliance attached for buccal movement of the maxillary first molar and the left side served as a control. Intermolar width was measured at 30 minutes, 7 days, and 14 days. Appliances were removed after 14 days and additional measurements were taken at 21 and 30 days. At the end of 14 days, the 
molars of the fiberotomy group had moved $0.54 \mathrm{~mm}$, compared to $0.26 \mathrm{~mm}$ in the apical flap group, and $0.3 \mathrm{~mm}$ in the no surgery group. Between 14 and 30 days, the relapse was $85 \%$ in the apical flap group and no surgery group, compared to $12 \%$ in the fiberotomy group. The sections of the maxillae of the rats showed significantly more alveolar bone loss, mostly of the PDL aspect of the buccal plate in the fiberotomy group. Bone resorption was seen in $27 \%$ of sections from the fiberotomy group, $12 \%$ of sections from the apical flap group, and $6 \%$ of sections in the no surgery group. Bone resorption specifically found on the buccal aspect was $20 \%, 12 \%$, and $0 \%$, respectively. The authors suggested that the increased bone resorption of the fiberotomy group was not due to the RAP, but instead to a strain relaxation of fibroblasts in the marginal gingiva. ${ }^{83,84} \mathrm{~A}$ limitation to this study, however, is the inherently small surgical field in the rat model and the concern that the distinction between a fiberotomy and a coronallyelevated flap may be difficult.

To date, no one has assessed the effect of flap elevation alone on the rate of tooth movement in the more clinically relevant dog model. In addition, the assessment of alveolar bone with microCT after flap elevation has not been reported. 


\section{CHAPTER II}

\section{PURPOSE AND SIGNIFICANCE}

The average duration of comprehensive orthodontic treatment has been an area of much research. Treatment duration ranges from 21-27 months for nonextraction treatment and from 25-35 months for extraction treatment. ${ }^{1-7}$ Orthodontic treatment time is influenced by many factors including type of malocclusion, amount of tooth movement required, mechanics utilized, and patient compliance. ${ }^{2,8,9}$ With prolonged orthodontic treatment time comes increased risk of root resorption, ${ }^{10,11}$ decalcification, ${ }^{12}$ and periodontal problems. ${ }^{13}$ In an effort to minimize these risks, orthodontists are continually trying to reduce treatment time, while providing treatment results equal to or better than those currently being delivered.

One way to reduce treatment time is to increase the rate of tooth movement. A currently popular way to facilitate the rate of tooth movement has been through the application of corticotomy surgeries. ${ }^{1,60,62,85}$ Experimental results have shown that corticotomies can approximately double the rate of tooth movement. ${ }^{65-67}$ The increase in the rate of tooth movement is through the induction of the regional acceleratory phenomenon (RAP). ${ }^{86}$

Corticotomy procedures insult the bone in two ways: elevation of a full-thickness mucoperiosteal flap to access the cortical bone and the corticotomies themselves. In an effort to reduce the amount of surgery involved, several studies have evaluated the effect of cortical bone damage without mucoperiosteal flap elevation. Safavi et a $1^{70}$ performed flapless bur decortications in dogs, which did not effect the rate of tooth movement. 
Recently, Swapp et al ${ }^{74}$ performed flapless microfractures of the cortical plates in dogs and also found no effect on the rate of tooth movement. The extent of cortical bone damage in these studies was similar to the extent of cortical bone damage associated with traditional corticotomy procedures, which accelerate tooth movements. As such, the difference among these results may be due to the elevation of a flap during corticotomies.

In 1994, Yaffe et al $^{79}$ showed that the RAP could be induced by elevation of a full-thickness mucoperiosteal flap alone in rats. The rat model has also been used to show increases in transverse maxillary tooth movement after fiberotomy. ${ }^{82}$ Due to the small size of rats, it is possible that both the flaps and fiberotomies are producing RAP effects that are so large that they cannot be distinguished. It would follow that the elevation of a mucoperiosteal flap from a coronal approach in the larger dog model, more representative of a human surgical field, should induce the RAP and that the RAP induced may be of a large enough scale to result in an increase of translatory orthodontic tooth movement.

The purpose of the present study was to determine if elevation of a flap alone is sufficient to initiate the RAP and accelerate tooth movement. The results will provide insights into the role of the flap in the RAP effect seen in corticotomy studies and may indicate the importance of planning periodontal flaps during surgeries meant to accelerate tooth movement. 


\section{CHAPTER III}

\section{MATERIALS AND METHODS}

Seven skeletally mature male beagle dogs, 9-12 months of age and weighing 2125 pounds, were used in this experiment. All of the animals had fully erupted dentitions and were healthy. The canine model was selected because it has been well established

for investigating tooth movements and bony adaptation. ${ }^{24,25}$ Housing, care, and experimental protocols were approved by the Institutional Animal Care and Use Committee at Texas A\&M University, Baylor College of Dentistry. During the course of the experiment, the dogs were fed a soft diet to minimize damage to the orthodontic appliances.

\section{Pre-Surgical Preparation}

Following a 10-day quarantine, initial records were taken. The animals were fasted for 12-hours and then sedated with an intramuscular injection of ketamine (8-24 $\mathrm{mg} / \mathrm{kg} \mathrm{IM})$ mixed with xylazine $(0.22 \mathrm{mg} / \mathrm{kg} \mathrm{IM})$. Dental prophylaxis using an ultrasonic scaler irrigated with $0.12 \%$ chlorhexidine gluconate was performed and bone markers [6 mm long Imtec miniscrew implants (3M Unitek, Monrovia, CA)] were placed for radiographic reference. A total of four markers were placed in the mandible, two on each side. The heads of the screws were removed to the level of the gingival tissue for animal comfort.

Right and left periapical radiographs were taken before and after bone marker placement using a size 4 film. A custom holder was designed to standardize film and xray tube angulations and distances (Figure 1). To standardize intra-oral measurements, 
notches were cut into the cusp tips of the canine and third premolar and at the most gingival aspect of the mesiobuccal groove of the first molar. Digital calipers (RadioShack, Fort Worth, TX) were used to measure to the nearest $0.01 \mathrm{~mm}$, the distance between the canine and third premolar, as well as the distance between the third premolar and first molar. Three replicate caliper measurements were made for each distance and averaged. Lastly, Triad custom tray material (Dentsply, York, PA) was used to make mandibular impression trays, and alginate impressions of the mandibles were taken. The impressions were poured in die stone and the models were used for appliance fabrication.

\section{Appliance Design}

Appliances were designed based on an established protocol. ${ }^{74}$ Orthodontic band material (Dentaurum, Ispringen, Germany) was custom pinched and welded to fit the mandibular canines and third premolars. Headgear tubes of 0.051 " diameter (3M Unitek, Monrovia, CA) were soldered to the orthodontic bands on the third premolars.

Orthodontic wire of 0.045 " diameter was soldered to the canine bands and inserted through the headgear tubes on the bands of the third premolars (Figure 2A). The wire was designed to have a loop at the distolingual aspect of the canine band to attach a spring at the time of appliance delivery. The third premolars were able to move freely along the wire. The interior aspect of each band was micro-abraded prior to cementation. For animal comfort, a ball of solder was placed on the distal end of the wire. 


\section{Surgical Protocol and Appliance Placement}

Following initial sedation with the ketamine and xylazine cocktail previously described, the dogs were intubated and administered $1-1.5 \%$ isoflurane in oxygen at a rate of $1 \mathrm{~L} / \mathrm{min}$. Vital signs were monitored throughout. Local anesthetic $(2 \%$ lidocaine with 1:100,000 epinephrine) was administered at the surgical sites via regional infiltration and an inferior alveolar block.

Both mandibular second premolars were sectioned, elevated, and extracted. The experimental surgical side was chosen using an electronically generated random number table. On the experimental side, a full-thickness mucoperiosteal flap was elevated from the distal aspect of the third premolar to the mesial aspect of the first premolar, with a vertical releasing incision at the mesial limit of the flap that went past the keratinized gingiva and into the level of the buccal mucosa (Figure 2B). After thorough flap elevation, the tissue was reapproximated with simple interrupted 4-0 Vicryl resorbable sutures.

A twelve-fluted carbide bur was used to remove calculus and debris from the teeth and retention grooves were cut around the canines and third premolars. The teeth were then etched with $37 \%$ phosphoric acid gel for $15 \mathrm{~s}$. After irrigating and drying the teeth, the appliance was cemented as a single unit on each side of the arch with lightcured RelyX Unicem (3M ESPE, St. Paul, MN) resin cement. Excess cement was removed to prevent gingival irritation.

The appliances were activated by attaching a $9 \mathrm{~mm}$ heavy NiTi coil (3M Unitek, Monrovia, CA) from the third premolar headgear tube attachment to the soldered wire 
loop on the canine using 0.012" stainless steel ligatures (Figure 2C). The springs were activated to $200 \mathrm{~g}$, which was verified using a Correx force gauge (Haag-Streit, Bern, Switzerland). Post-operative periapical radiographs were taken.

Immediately after surgery the dogs were given a single dose of ketoprofen (1

$\mathrm{mg} / \mathrm{kg} \mathrm{IM}$ ). For the next week they were also given post-operative analgesic (nalbuphine $2 \mathrm{mg} / \mathrm{kg} \mathrm{IM}$ ) and antibiotics (clindamycin $11 \mathrm{mg} / \mathrm{kg} \mathrm{IM}$ ) twice daily.

\section{Measurements and Appliance Reactivation}

Intra-oral caliper measurements and periapical radiographs were taken every two weeks for eight weeks after surgery. At each of these occasions, the NiTi spring was retied to insure it was still delivering $200 \mathrm{~g}$ of force.

\section{Euthanasia}

After eight weeks of third premolar protraction (day 56), the animals were again sedated with the previously described ketamine and xylazine cocktail and final records were obtained, including periapical radiographs, caliper measurements, and impressions. Surgical plane anesthesia was then confirmed and the common carotid arteries were both cannulated and the external jugular veins severed. An intracardial injection of $2 \mathrm{cc}$ beuthanasia-D was given. After cessation of heart function was confirmed, approximately $1.5 \mathrm{~L}$ of saline followed by $1 \mathrm{~L}$ of $70 \%$ ethanol was flushed through the cannulas. The mandible was then harvested and stored in $70 \%$ ethanol.

\section{Radiographic Analysis of Movement}

Periapical radiographs were imported into Viewbox 4.0 (DHAL Software, Kifissia, Greece). Through assessment of radiographic superimpositions on the bone 
markers, the mesial and distal alveolar crests of the fourth premolar were found to be stable points during the course of the experiment. A line connecting the alveolar crests of the fourth premolar was used as a reference plane to assess tipping.

Using a custom protocol, all radiographs were analyzed to assess translation and tipping of the third premolar. The mesial and distal alveolar crest of the fourth premolar, mesial and distal root apices of the third premolar, and furcation of the third premolar were digitized. From these landmarks, the midpoint between the roots of the third premolar was calculated and the line from this root midpoint to the furcation of the third premolar was digitized to represent the long axis of the tooth. The angle formed between the long axis of the third premolar and the alveolar crest reference plane was used to assess tipping of the tooth during protraction. Additionally, the midpoint of the furcal bone along the long axis of the third premolar was calculated and used as an approximate center of resistance of the tooth to better assess pure translation of the tooth during the experiment. This midpoint was projected perpendicularly onto the reference plane and the distance from this projected point to the mesial crest of the fourth premolar was measured as the distance of tooth translation (Figure 3).

Superimposition of the radiographs in Viewbox 4.0 software confirmed the overall assessment of tipping and translation that was measured using the custom protocol described above.

\section{MicroCT Assessment of Bone Density}

After sacrifice, all specimens were stripped of soft tissue, sectioned to fit in microCT tubes $27 \mathrm{~mm}$ in diameter, and scanned using the Scanco $\mu \mathrm{CT} 35$ scanner 
(ScanCo Medical, Basserdorf, Switzerland). The entire surgical site and third premolar were scanned. The specimens were stabilized so that the occlusal plane was approximately perpendicular to the long axis of the specimen tubes, which were filled with 70\% ethanol and sealed with Parafilm (Pechiney Plastic Packaging Company, Chicago, IL).

The specimens were imaged at $30 \mu \mathrm{m}$ resolution, $55 \mathrm{kVp}, 145 \mu \mathrm{A}$ and $600 \mathrm{~ms}$ integration time. Mesial bone volumes relative to the third premolar were segmented and analyzed with the Scanco Micro-CT v.6.0 software. This segment of bone was chosen due to its location within the experimental surgical flap area. Also, this area is of specific interest because it is the bone into which the third premolar is being moved and as such the properties of this bone would be important to the rate of tooth movement. Bone volume/total volume, apparent bone density, and material bone density were measured on both the control and experimental sides.

The mesial medullary bone area analyzed was approximately $1 \mathrm{~mm} \times 3 \mathrm{~mm} \times 1.4$ $\mathrm{mm}$. For each specimen the slice containing distal root apex of the third premolar was located. The inferior limit was then set an additional 25 slices apically from that plane. The superior limit was 50 slices coronal from the inferior limit. This resulted in an effective measurement depth of $1.44 \mathrm{~mm}$. The lateral limit was set mesial to the mesial root of the third premolar in the most coronal slice and a rectangle of approximately 1 $\mathrm{mm}$ by $3 \mathrm{~mm}$ was defined within the center of the medullary bone space running parallel to the lingual cortex (Figure 6). This rectangle was then projected down the 50 slices of interest. 
After defining the mesial bone volumes, the images were smoothed with a Gausian filter of sigma equal to 0.9 and support equal to 1 . Volumes were segmented at a minimum threshold of 270 .

\section{Histologic Evaluation of Specimens}

After the microCT evaluation, the specimens were cut to harvest the bone immediately mesial to the third mandibular premolar and distal to the first premolar. This section was removed and cut to include the bone from the alveolar crest to the level of the mental foramina, which was at least beyond the level of the mesial root apex of the third premolar. The specimens were decalcified in ethylenediaminetetraacetic acid, dehydrated in graded alcohol, cleared with xylene, then infiltrated and embedded in paraffin. After sectioning the block in a coronal orientation into slices with a thickness of 5-10 $\mu \mathrm{m}$, starting with the section closest to the mesial root of the third premolar, every sixth section was selected for a total of 6 sections to be mounted. These sections were mounted to glass slides and stained with hematoxylin and eosin to evaluate osteoclast populations. The slides were visualized and photographed under a Nikon Eclipse 80i microscope.

\section{Statistical Analyses}

Multilevel statistical models were used to statistically determine the shape of the curve describing tooth movement and differences between the experimental and control sides. The multilevel models were developed using the MLwiN software (version 2.01, Center for Multilevel Modeling, Institute of Education, London, UK). The iterative generalized least squares method was used to estimate model parameters. 
Each model's fixed portion allowed for determination of the polynomial that best fit the repeated measurements of tooth movement as a function of time. The terms of the polynomial were derived by initially fitting third order polynomials and testing the terms statistically. Based on standard error, the higher order terms of the polynomial were rejected in a sequential fashion until a lower order term attained significance $(\mathrm{p}<0.05)$. The constant terms described the tooth movement at day 56, the linear terms described the rate of change (velocity), and the quadratic terms described the change in rate (acceleration).

Data from the microCT analysis were described using means and standard deviations (SPSS software version 22.0, Armonk, NY). The experimental and control sides were compared using Wilcoxon signed rank tests using 1-tailed tests and a significance level of $\mathrm{p}<0.05$. 


\section{CHAPTER IV}

RESULTS

After surgery, healing proceeded normally without any signs of swelling or infection. During the course of the experiment, four dogs had damaged appliances due to either bond failure or spring detachment (Table 1). All appliances were repaired the same day breakage was detected, and no more than 48 hours after the damage occurred. The tooth movements of Dog F were not evaluated, due to an excessive number of appliance breakages and aberrant tipping of the third premolars.

Intraoral caliper measurements showed that the third premolar was protracted mesially. Multilevel analysis showed that the tooth movements followed a quadratic pattern and that there were significant differences in the total amount of tooth movement $(\mathrm{p}<0.01)$ and rate of tooth movement $(\mathrm{p}<0.05)$ for both intraoral measurements (Table

2). The distance between the third premolar and first molar increased $3.09 \mathrm{~mm}$ and 3.86

$\mathrm{mm}$ for the control and experimental sides, respectively (Figure 4A). The distance between the canine and third premolar showed that these teeth were approximated by a cumulative distance of $4.61 \mathrm{~mm}$ and $5.56 \mathrm{~mm}$ for the control and experimental sides, respectively (Figure 4B).

Radiographic measurements showed that the total amount of translation of the approximate center of resistance of the third premolar was $1.28 \mathrm{~mm}$ on the control side and $1.68 \mathrm{~mm}$ on the experimental side. Translation of the third premolar followed a quadratic curve with significant differences in the total amount of translation $(\mathrm{p}<0.05)$ and in the rate of translation $(\mathrm{p}<0.01)$ (Table 2, Figure 5A). Third premolars tipped $7.30^{\circ}$ 
on the control side and $10.12^{\circ}$ on the experimental side. Tipping followed a linear pattern with no significant differences between the control and experimental sides (Table 2, Figure 5B).

All seven dogs were included for the microCT assessment. The mesial medullary bone volume fraction was significantly less $(\mathrm{p}<0.05)$ on the experimental side than on the control side (Table 3$)$. Apparent density was also significantly lower $(\mathrm{p}<0.05)$ on the experimental side than on the control side. Material density was lower on the experimental side compared to the control, however, the difference was not significant. Similarly, trabecular number, trabecular thickness, and trabecular spacing were all less on the experimental side, however, none of the differences were statistically significant. Assessment of the histologic sections did not show significant differences. Osteoblasts lined the surfaces of the bone and mature multinucleated osteoclasts were present. However, there was no consistent pattern between experimental and control bone that could be clearly discerned among the different animals. 


\section{CHAPTER V}

\section{DISCUSSION}

Elevation of a full-thickness mucoperiosteal flap alone increases the rate of mesio-distal orthodontic tooth movement. In the present study, flap elevation increased the rate of tooth movement by approximately $25 \%$. The increased rate of tooth movement produced by flap-only surgery is substantially less than previously reported with corticotomy procedures. Split-mouth studies that protract the mandibular third premolars in beagles show $100 \%$ increases in tooth movement when both corticotomies and full-thickness flaps are performed. ${ }^{65,66}$ Sanjideh et $\mathrm{al}^{67}$ reported a $67 \%$ increase retracting the mandibular second premolar with corticotomies and flaps in beagles. A split-mouth human study comparing surgical canine exposure ${ }^{63}$ found $41.3 \%$ greater tooth during canine retraction with additional corticotomies. The smaller effects in the present study were probably due to the more limited injury. Increased rates of tooth movement have been previously associated with increases in surgical insult to the bone. ${ }^{67,87}$ When the insult to the bone is increased, an increase in the regional acceleratory phenomenon occurs. ${ }^{51-53,69}$ It is to be expected that the insult of stripping away the periosteal blood supply when elevating a full-thickness mucoperiosteal flap would be less than that experienced in the corticotomy procedure in which both a fullthickness mucoperiosteal flap is laid and cuts are made in the cortical bone.

Other studies that have did not control for tipping may have overestimated the amount of tooth movement that occurred. In the present study, tipping of the third premolar occurred during protraction on both the control and experimental sides. 
Radiographic measurement of translation at the approximate center of resistance of the tooth showed that less tooth movement occurred at the center of resistance than at the crowns ( $1.68 \mathrm{~mm}$ vs $3.86 \mathrm{~mm}$ on the experimental side). However, there were significant side differences, with $31 \%$ greater tooth movement on the experimental side. This novel approach for measuring translation is important because it is the only way to control for the potentially confounding effects of tipping.

Elevation of a full-thickness mucoperiosteal flap increases tooth movements because it decreases the amount and apparent density of the medullary bone. In the present study, the mesial medullary bone in the area of the flap showed $9 \%$ less bone volume fraction and $9 \%$ less apparent density than control bone. Decreases in bone volume fraction and density have been shown to be associated with the RAP effect to varying degrees. ${ }^{69,86,88}$ A flapless piezocision experiment in the beagle maxilla by Ruso et al shows a similar trend in changes in the medullary bone regarding bone volume fraction and material density compared to the present study. ${ }^{89}$ While the material density of the bone in the present study was less on the experimental side compared to the control side it was not statistically significant. It is possible that a larger sample size would have found significance in the decrease in the material density.

Medullary bone maturity might also be affected by elevation of a full-thickness mucoperiosteal flap. In the present study, the experimental side tended to show a greater trabecular number, less trabecular thickness, and less trabecular separation than the control bone. This pattern is indicative of newly formed bone. Increased trabecular number and decreased trabecular size and spacing has been previously associated with 
faster tooth movements associated with greater surgical insult. ${ }^{69}$ Significant increases in trabecular number and significant decreases in trabecular thickness in cases of distraction osteogenesis have also been reported. ${ }^{90,91}$ The differences in the trabecular bone in the present study would likely have been statistically significant with a larger sample size. As previously indicated, the trabecular bone effects were less due to the more limited biological insult that the bone was subjected to.

Elevation of the periosteum alone provides sufficient disruption of the circulation to the bone to stimulate the RAP, as evident by the changes in bone volume fraction observed in the present study. In long bones the periosteum is responsible for up to 70 $80 \%$ of the arterial supply to cortical bone, as well as $100 \%$ of venous return. ${ }^{75}$ Additionally, it has been shown that in cases of damaged periosteum, cortical bone relies more heavily on the centromedullary arterial supply, receiving up to $30-40 \%$ of its arterial supply from the centromedullary blood system in those cases. ${ }^{75}$ Insufficient disruption of the circulation of the bone may explain why experiments assessing flapless microfracture and corticision surgery have not produced the RAP in bone into which the teeth were moved and why tooth movements were not increased. ${ }^{74,92}$ If bone damage is limited to the cortical bone and neither the periosteal nor centromedullary bone supplies are disrupted, then bone density and tooth movement remain unaffected. ${ }^{74,92}$ Only in flapless corticision experiments that disrupt medullary bone have reported significant increases in tooth movement. ${ }^{72}$

No consistent pattern was seen regarding presence of osteoclasts and osteoblasts in the medullary bone among the animals. It is likely that the differences between the 
experimental and control sides that must have occurred were no longer apparent eight weeks after flap elevation. Sebaoun et $\mathrm{al}^{86}$ in a rat corticotomy study showed that osteoclast count was not different from that in control bone at seven and eleven weeks post-surgery. In contrast, McBride et $\mathrm{al}^{69}$ showed a significantly greater number of osteoclasts present at nine weeks post-surgery, on the side of the jaw that had the more extensive surgical insult. The present study's more limited surgical insult of only flapelevation might be expected to produce a lesser overall bone response. As such, the combination of a longer healing time (eight weeks) and limited surgery could explain the lack of difference in osteoclasts and osteoblasts observed in the experimental and control medullary bone.

\section{Clinical Implications}

Clinically, elevation of a full-thickness flap from a coronal approach to increase rates of tooth movement may not be justified. Performing a standalone flap surgery for a $25-31 \%$ increase in the rate of tooth movement requires careful consideration because flap elevation can produce alveolar bone loss. ${ }^{81,93,94}$ However, if surgery is being performed for other purposes, the benefit of the increased rate of tooth movement due to flap elevation should be considered. For example, in cases of premolar extraction, the clinician might choose to elevate a flap at the time of extraction if orthodontic treatment is being initiated immediately. This is recommended based on the lack of significant

difference in the long-term healing of the bone after extractions with or without a flap. ${ }^{95}$ In fact, local corticotomies could also be added at the same time as extraction and flap elevation to further enhance the effect. Likewise, corticotomy procedures might be 
expected to benefit from reflection of a full-thickness flap from a coronal approach during the procedure rather than attempting flapless corticotomy. 


\section{CHAPTER VI CONCLUSIONS}

1. Full-thickness mucoperiosteal flap elevation increases the rate of orthodontic tooth movements.

2. Flap elevation decreases the bone volume fraction of medullary bone in the surgical area, allowing for the acceleration of tooth movement.

3. No histologic differences in presence of osteoclasts or osteoblasts were seen at eight weeks after flap elevation between the experimental and control sides. 


\section{REFERENCES}

1. Buschang PH, Campbell PM, Ruso S. Accelerating Tooth Movement With Corticotomies: Is It Possible and Desirable? Seminars in Orthodontics 2012;18:286-294.

2. Skidmore KJ, Brook KJ, Thomson WM, Harding WJ. Factors influencing treatment time in orthodontic patients. Am J Orthod Dentofacial Orthop 2006;129:230-238.

3. Fink DF, Smith RJ. The duration of orthodontic treatment. American Journal of Orthodontics and Dentofacial Orthopedics 1992;102:45-51.

4. Alger DW. Appointment frequency versus treatment time. American Journal of Orthodontics and Dentofacial Orthopedics 1988;94:436-439.

5. Popowich K, Nebbe B, Heo G, Glover KE, Major PW. Predictors for Class II treatment duration. American Journal of Orthodontics and Dentofacial Orthopedics 2005; 127:293-300.

6. Vu CQ, Roberts WE, Hartsfield Jr JK, Ofner S. Treatment complexity index for assessing the relationship of treatment duration and outcomes in a graduate orthodontics clinic. American Journal of Orthodontics and Dentofacial Orthopedics 2008;133:9.e19.e13.

7. O'Brien KD, Robbins R, Vig KWL, Vig PS, Shnorhokian H, Weyant R. The effectiveness of Class II, Division 1 treatment. American Journal of Orthodontics and Dentofacial Orthopedics 1995;107:329-334.

8. Beckwith FR, Ackerman RJ, Jr., Cobb CM, Tira DE. An evaluation of factors affecting duration of orthodontic treatment. Am J Orthod Dentofacial Orthop 1999;115:439-447.

9. Fisher MA, Wenger RM, Hans MG. Pretreatment characteristics associated with orthodontic treatment duration. Am J Orthod Dentofacial Orthop 2010;137:178-186.

10. Kurol J, Owman-Moll P, Lundgren D. Time-related root resorption after application of a controlled continuous orthodontic force. Am J Orthod Dentofacial Orthop 1996;110:303-310.

11. Segal GR, Schiffman PH, Tuncay OC. Meta analysis of the treatment-related factors of external apical root resorption. Orthod Craniofac Res 2004;7:71-78.

12. Artun J, Brobakken BO. Prevalence of carious white spots after orthodontic treatment with multibonded appliances. Eur J Orthod 1986;8:229-234. 
13. Ristic M, Vlahovic Svabic M, Sasic M, Zelic O. Clinical and microbiological effects of fixed orthodontic appliances on periodontal tissues in adolescents. Orthod Craniofac Res 2007;10:187-195.

14. Boester $\mathrm{CH}$, Johnston LE. A clinical investigation of the concepts of differential and optimal force in canine retraction. Angle Orthod 1974;44:113-119.

15. Samuels RH, Rudge SJ, Mair LH. A comparison of the rate of space closure using a nickel-titanium spring and an elastic module: a clinical study. Am J Orthod Dentofacial Orthop 1993;103:464-467.

16. Samuels RH, Rudge SJ, Mair LH. A clinical study of space closure with nickeltitanium closed coil springs and an elastic module. Am J Orthod Dentofacial Orthop 1998;114:73-79.

17. Iwasaki LR, Haack JE, Nickel JC, Morton J. Human tooth movement in response to continuous stress of low magnitude. Am J Orthod Dentofacial Orthop 2000;117:175183.

18. Nightingale C, Jones SP. A clinical investigation of force delivery systems for orthodontic space closure. J Orthod 2003;30:229-236.

19. Ren Y, Maltha JC, Van 't Hof MA, Kuijpers-Jagtman AM. Optimum force magnitude for orthodontic tooth movement: a mathematic model. Am J Orthod Dentofacial Orthop 2004;125:71-77.

20. Daskalogiannakis J, McLachlan KR. Canine retraction with rare earth magnets: an investigation into the validity of the constant force hypothesis. Am J Orthod Dentofacial Orthop 1996;109:489-495.

21. Burrow SJ. Canine retraction rate with self-ligating brackets vs conventional edgewise brackets. Angle Orthod 2010;80:438-445.

22. Scott P, DiBiase AT, Sherriff M, Cobourne MT. Alignment efficiency of Damon3 self-ligating and conventional orthodontic bracket systems: A randomized clinical trial. American Journal of Orthodontics and Dentofacial Orthopedics 2008;134:470.e471470.e478.

23. da Costa Monini A, Júnior LGG, Martins RP, Vianna AP. Canine retraction and anchorage loss: Self-ligating versus conventional brackets in a randomized split-mouth study. The Angle Orthodontist 2014;84:846-852. 
24. Aerssens J, Boonen S, Lowet G, Dequeker J. Interspecies differences in bone composition, density, and quality: potential implications for in vivo bone research. Endocrinology 1998;139:663-670.

25. Wang X, Mabrey JD, Agrawal CM. An interspecies comparison of bone fracture properties. Biomed Mater Eng 1998;8:1-9.

26. Pilon JJ, Kuijpers-Jagtman AM, Maltha JC. Magnitude of orthodontic forces and rate of bodily tooth movement. An experimental study. Am J Orthod Dentofacial Orthop 1996;110:16-23.

27. Owens SE, Buschang PH, Cope JB, Franco PF, Rossouw PE. Experimental evaluation of tooth movement in the beagle dog with the mini-screw implant for orthodontic anchorage. Am J Orthod Dentofacial Orthop 2007;132:639-646.

28. Carrillo R, Rossouw PE, Franco PF, Opperman LA, Buschang PH. Intrusion of multiradicular teeth and related root resorption with mini-screw implant anchorage: A radiographic evaluation. American Journal of Orthodontics and Dentofacial Orthopedics 2007;132:647-655.

29. van Leeuwen EJ, Maltha JC, Kuijpers-Jagtman AM. Tooth movement with light continuous and discontinuous forces in beagle dogs. Eur J Oral Sci 1999;107:468-474.

30. Gross D, Williams WS. Streaming potential and the electromechanical response of physiologically-moist bone. J Biomech 1982;15:277-295.

31. Davidovitch Z, Finkelson MD, Steigman S, Shanfeld JL, Montgomery PC, Korostoff E. Electric currents, bone remodeling, and orthodontic tooth movement. II. Increase in rate of tooth movement and periodontal cyclic nucleotide levels by combined force and electric current. Am J Orthod 1980;77:33-47.

32. Bassett CA, Becker RO. Generation of electric potentials by bone in response to mechanical stress. Science 1962;137:1063-1064.

33. Davidovitch Z, Finkelson MD, Steigman S, Shanfeld JL, Montgomery PC, Korostoff E. Electric currents, bone remodeling, and orthodontic tooth movement. I. The effect of electric currents on periodontal cyclic nucleotides. Am J Orthod 1980;77:14-32.

34. Burger EH, Klein-Nulend J. Mechanotransduction in bone--role of the lacunocanalicular network. Faseb j 1999;13 Suppl:S101-112.

35. Moss ML. The functional matrix hypothesis revisited. 2. The role of an osseous connected cellular network. Am J Orthod Dentofacial Orthop 1997;112:221-226. 
36. Moss ML. The functional matrix hypothesis revisited. 1. The role of mechanotransduction. Am J Orthod Dentofacial Orthop 1997;112:8-11.

37. Bister D, Meikle MC. Re-examination of 'Einige Beiträge zur Theorie der Zahnregulierung' (Some contributions to the theory of the regulation of teeth) published in 1904-1905 by Carl Sandstedt. European Journal of Orthodontics 2013;35:160-168.

38. Oppenheim A. Tissue changes, particularly of the bone, incident to tooth movement. European Journal of Orthodontics 2007;29:i2-i15.

39. Schwarz AM. Tissue changes incidental to orthodontic tooth movement. International Journal of Orthodontia, Oral Surgery and Radiography 1932;18:331-352.

40. Reitan K. Clinical and histologic observations on tooth movement during and after orthodontic treatment. American Journal of Orthodontics 1967;53:721-745.

41. Proffit WF, HG; Sarver, D. Contemporary Orthodontics. St. Louis, MO: Mosby, Inc.; 2007.

42. King GJ, Keeling SD, Wronski TJ. Histomorphometric study of alveolar bone turnover in orthodontic tooth movement. Bone 1991;12:401-409.

43. Verna C, Dalstra M, Melsen B. The rate and the type of orthodontic tooth movement is influenced by bone turnover in a rat model. Eur J Orthod 2000;22:343-352.

44. Goldie RS, King GJ. Root resorption and tooth movement in orthodontically treated, calcium-deficient, and lactating rats. Am J Orthod 1984;85:424-430.

45. Ashcraft MB, Southard KA, Tolley EA. The effect of corticosteroid-induced osteoporosis on orthodontic tooth movement. Am J Orthod Dentofacial Orthop 1992;102:310-319.

46. Collins MK, Sinclair PM. The local use of vitamin D to increase the rate of orthodontic tooth movement. Am J Orthod Dentofacial Orthop 1988;94:278-284.

47. Kobayashi Y, Takagi H, Sakai H, Hashimoto F, Mataki S, Kobayashi K et al. Effects of local administration of osteocalcin on experimental tooth movement. Angle Orthod 1998;68:259-266.

48. Yamasaki K, Shibata Y, Fukuhara T. The effect of prostaglandins on experimental tooth movement in monkeys (Macaca fuscata). J Dent Res 1982;61:1444-1446. 
49. Yamasaki K, Shibata Y, Imai S, Tani Y, Shibasaki Y, Fukuhara T. Clinical application of prostaglandin E1 (PGE1) upon orthodontic tooth movement. Am J Orthod 1984;85:508-518.

50. Ortega AJ, Campbell PM, Hinton R, Naidu A, Buschang PH. Local application of zoledronate for maximum anchorage during space closure. Am J Orthod Dentofacial Orthop 2012;142:780-791.

51. Frost HM. The regional acceleratory phenomenon: a review. Henry Ford Hosp Med J 1983;31:3-9.

52. Frost HM. The biology of fracture healing. An overview for clinicians. Part II. Clin Orthop Relat Res 1989:294-309.

53. Frost HM. The biology of fracture healing. An overview for clinicians. Part I. Clin Orthop Relat Res 1989:283-293.

54. Melsen B. Biological reaction of alveolar bone to orthodontic tooth movement. Angle Orthod 1999;69:151-158.

55. Kole H. Surgical operations on the alveolar ridge to correct occlusal abnormalities. Oral Surg Oral Med Oral Pathol 1959;12:413-420 contd.

56. Kole H. Surgical operations on the alveolar ridge to correct occlusal abnormalities. Oral Surg Oral Med Oral Pathol 1959;12:277-288 contd.

57. Kole H. Surgical operations on the alveolar ridge to correct occlusal abnormalities. Oral Surg Oral Med Oral Pathol 1959;12:515-529 concl.

58. Gantes B, Rathbun E, Anholm M. Effects on the periodontium following corticotomy-facilitated orthodontics. Case reports. J Periodontol 1990;61:234-238.

59. Duker J. Experimental animal research into segmental alveolar movement after corticotomy. J Maxillofac Surg 1975;3:81-84.

60. Wilcko WM, Wilcko T, Bouquot JE, Ferguson DJ. Rapid orthodontics with alveolar reshaping: two case reports of decrowding. Int $\mathrm{J}$ Periodontics Restorative Dent 2001;21:9-19.

61. Murphy KG, Wilcko MT, Wilcko WM, Ferguson DJ. Periodontal Accelerated Osteogenic Orthodontics: A Description of the Surgical Technique. Journal of Oral and Maxillofacial Surgery 2009;67:2160-2166. 
62. Wilcko MT, Wilcko WM, Pulver JJ, Bissada NF, Bouquot JE. Accelerated osteogenic orthodontics technique: a 1-stage surgically facilitated rapid orthodontic technique with alveolar augmentation. J Oral Maxillofac Surg 2009;67:2149-2159.

63. Fischer TJ. Orthodontic treatment acceleration with corticotomy-assisted exposure of palatally impacted canines. Angle Orthod 2007;77:417-420.

64. Lee JK, Chung KR, Baek SH. Treatment outcomes of orthodontic treatment, corticotomy-assisted orthodontic treatment, and anterior segmental osteotomy for bimaxillary dentoalveolar protrusion. Plast Reconstr Surg 2007;120:1027-1036.

65. Cho KW, Cho SW, Oh CO, Ryu YK, Ohshima H, Jung HS. The effect of cortical activation on orthodontic tooth movement. Oral Dis 2007;13:314-319.

66. Iino S, Sakoda S, Ito G, Nishimori T, Ikeda T, Miyawaki S. Acceleration of orthodontic tooth movement by alveolar corticotomy in the dog. Am J Orthod Dentofacial Orthop 2007;131:448.e441-448.

67. Sanjideh PA, Rossouw PE, Campbell PM, Opperman LA, Buschang PH. Tooth movements in foxhounds after one or two alveolar corticotomies. Eur J Orthod 2010;32:106-113.

68. Cohen G, Campbell PM, Rossouw PE, Buschang PH. Effects of increased surgical trauma on rates of tooth movement and apical root resorption in foxhound dogs. Orthod Craniofac Res 2010;13:179-190.

69. McBride MD, Campbell PM, Opperman LA, Dechow PC, Buschang PH. How does the amount of surgical insult affect bone around moving teeth? American Journal of Orthodontics and Dentofacial Orthopedics 2014;145:S92-S99.

70. Safavi SM, Heidarpour M, Izadi SS, Heidarpour M. Effects of flapless bur decortications on movement velocity of dogs' teeth. Dent Res J (Isfahan) 2012;9:783789.

71. Kim SJ, Moon SU, Kang SG, Park YG. Effects of low-level laser therapy after Corticision on tooth movement and paradental remodeling. Lasers Surg Med 2009;41:524-533.

72. Kim SJ, Park YG, Kang SG. Effects of Corticision on paradental remodeling in orthodontic tooth movement. Angle Orthod 2009;79:284-291.

73. Alikhani M, Raptis M, Zoldan B, Sangsuwon C, Lee YB, Alyami B et al. Effect of micro-osteoperforations on the rate of tooth movement. Am J Orthod Dentofacial Orthop 2013;144:639-648. 
74. Swapp A. Cortical Bone Damage Does Not Accelerate Mesial-Distal Tooth Movement Orthodontics and Oral Biology: Texas A\&M Health Science Center, Baylor College of Dentistry; 2012.

75. Chanavaz M. Anatomy and histophysiology of the periosteum: quantification of the periosteal blood supply to the adjacent bone with $85 \mathrm{Sr}$ and gamma spectrometry. J Oral Implantol 1995;21:214-219.

76. High WB, Black HE, Capen CC. Histomorphometric evaluation of the effects of low dose parathyroid hormone administration on cortical bone remodeling in adult dogs. Lab Invest 1981;44:449-454.

77. High WB, Capen CC, Black HE. Histomorphometric evaluation of the effects of intermittent 1,25-dihydroxycholecalciferol administration on cortical bone remodeling in adult dogs. Am J Pathol 1981;104:41-49.

78. High WB, Capen CC, Black HE. Effects of thyroxine on cortical bone remodeling in adult dogs: a histomorphometric study. Am J Pathol 1981;102:438-446.

79. Yaffe A, Fine N, Binderman I. Regional accelerated phenomenon in the mandible following mucoperiosteal flap surgery. J Periodontol 1994;65:79-83.

80. Binderman I, Adut M, Zohar R, Bahar H, Faibish D, Yaffe A. Alveolar bone resorption following coronal versus apical approach in a mucoperiosteal flap surgery procedure in the rat mandible. J Periodontol 2001;72:1348-1353.

81. Fickl S, Kebschull M, Schupbach P, Zuhr O, Schlagenhauf U, Hurzeler MB. Bone loss after full-thickness and partial-thickness flap elevation. J Clin Periodontol 2011;38:157-162.

82. Young L, Binderman I, Yaffe A, Beni L, Vardimon AD. Fiberotomy enhances orthodontic tooth movement and diminishes relapse in a rat model. Orthod Craniofac Res 2013;16:161-168.

83. Binderman I, Bahar H, Yaffe A. Strain relaxation of fibroblasts in the marginal periodontium is the common trigger for alveolar bone resorption: a novel hypothesis. $\mathrm{J}$ Periodontol 2002;73:1210-1215.

84. Binderman I, Gadban N, Bahar H, Herman A, Yaffe A. Commentary on: periodontally accelerated osteogenic orthodontics (PAOO) - a clinical dilemma. Int Orthod 2010;8:268-277.

85. Wilcko W, Wilcko MT. Accelerating tooth movement: the case for corticotomyinduced orthodontics. Am J Orthod Dentofacial Orthop 2013;144:4-12. 
86. Sebaoun JD, Kantarci A, Turner JW, Carvalho RS, Van Dyke TE, Ferguson DJ. Modeling of trabecular bone and lamina dura following selective alveolar decortication in rats. J Periodontol 2008;79:1679-1688.

87. Cohen G, Campbell PM, Rossouw PE, Buschang PH. Effects of increased surgical trauma on rates of tooth movement and apical root resorption in foxhound dogs.

Orthodontics \& Craniofacial Research 2010;13:179-190.

88. Lee W, Karapetyan G, Moats R, Yamashita DD, Moon HB, Ferguson DJ et al. Corticotomy-/osteotomy-assisted tooth movement microCTs differ. J Dent Res 2008;87:861-867.

89. Ruso S, Campbell PM, Rossmann J, Opperman LA, Taylor RW, Buschang PH. Bone response to buccal tooth movements - with and without flapless alveolar decortication. The European Journal of Orthodontics 2014;36:613-623.

90. Moore C, Campbell PM, Dechow PC, Ellis ML, Buschang PH. Effects of latency on the quality and quantity of bone produced by dentoalveolar distraction osteogenesis. American Journal of Orthodontics and Dentofacial Orthopedics 2011;140:470-478.

91. Spencer AC, Campbell PM, Dechow P, Ellis ML, Buschang PH. How does the rate of dentoalveolar distraction affect the bone regenerate produced? American Journal of Orthodontics and Dentofacial Orthopedics 2011;140:e211-e221.

92. Murphy CA, Chandhoke T, Kalajzic Z, Flynn R, Utreja A, Wadhwa S et al. Effect of corticision and different force magnitudes on orthodontic tooth movement in a rat model. American Journal of Orthodontics and Dentofacial Orthopedics 2014;146:55-66.

93. Tavtigian R. The Height of the Facial Radicular Alveolar Crest Following Apically Positioned Flap Operations. Journal of Periodontology 1970;41:412-418.

94. Wood DL, Hoag PM, Donnenfeld OW, Rosenfeld LD. Alveolar Crest Reduction Following Full and Partial Thickness Flaps. Journal of Periodontology 1972;43:141-144.

95. Araújo MG, Lindhe J. Ridge alterations following tooth extraction with and without flap elevation: an experimental study in the dog. Clinical Oral Implants Research 2009;20:545-549. 


\section{APPENDIX A}

\section{FIGURES}

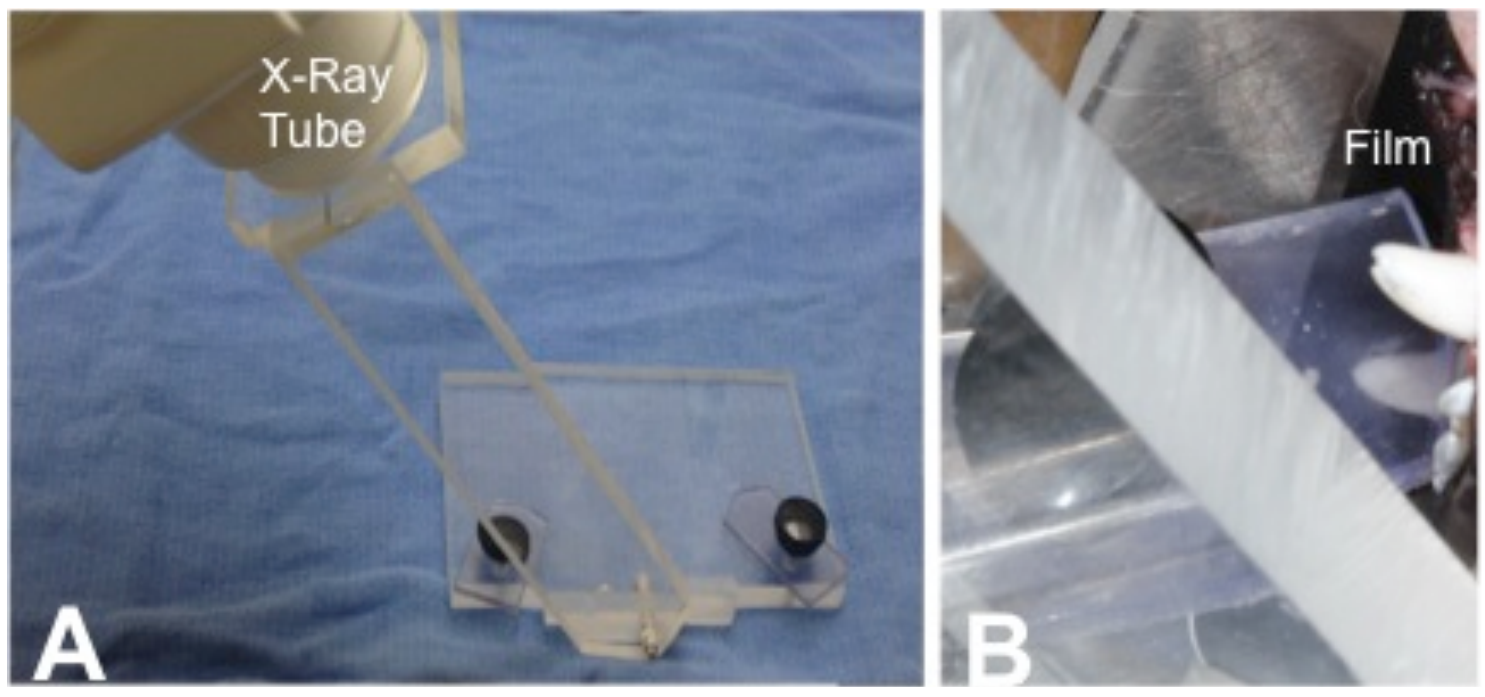

Figure 1. Standardized radiographic holder. A) Custom x-ray holder with tube head maintained at constant angle and distance. B) Subject positioned in the x-ray holder with film in place. 


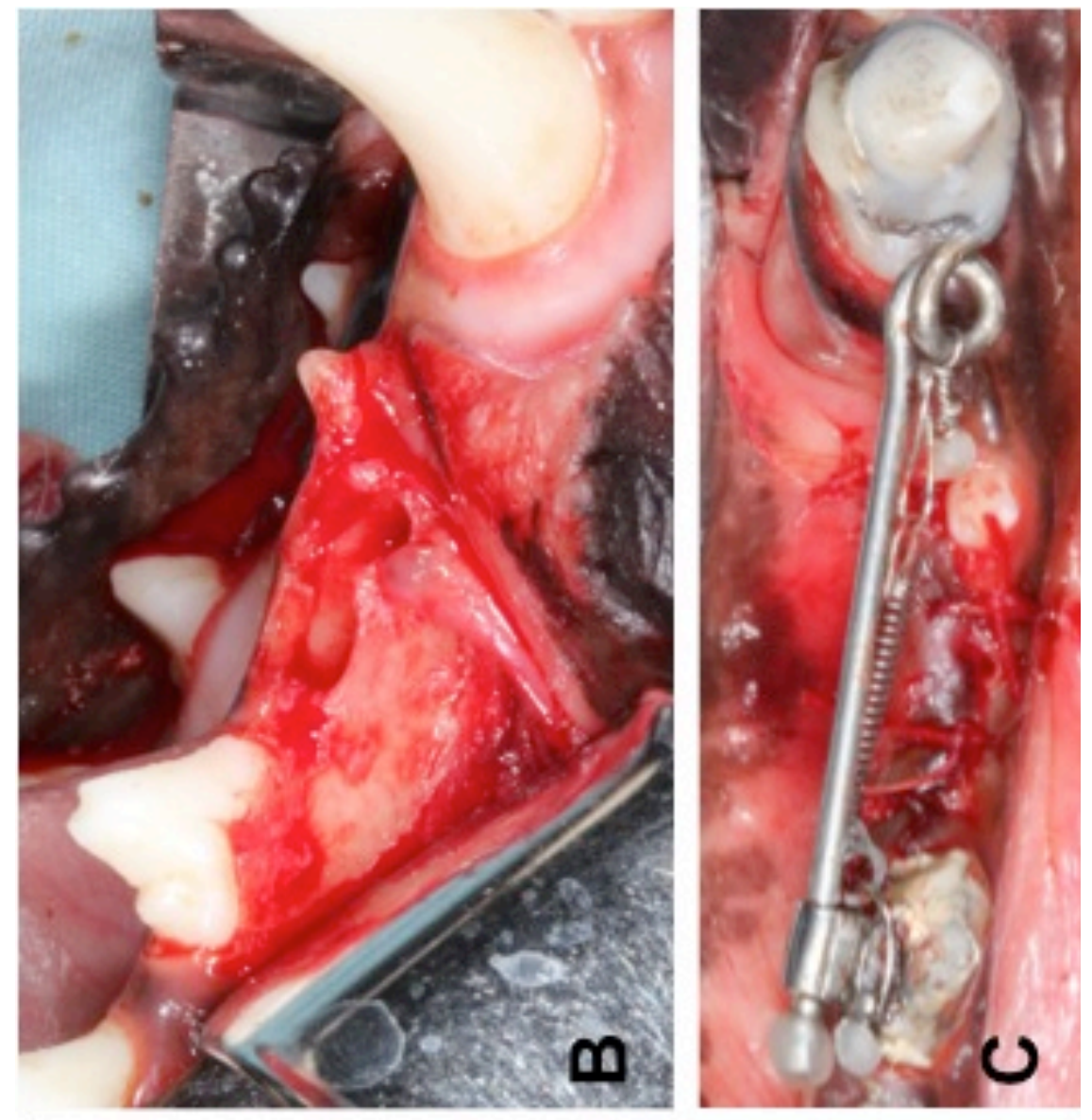

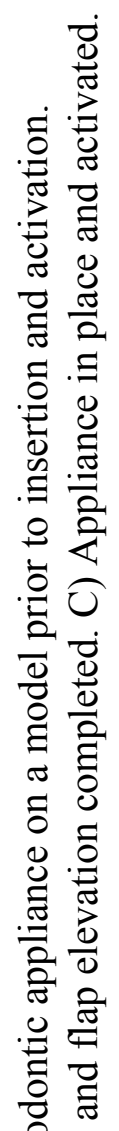

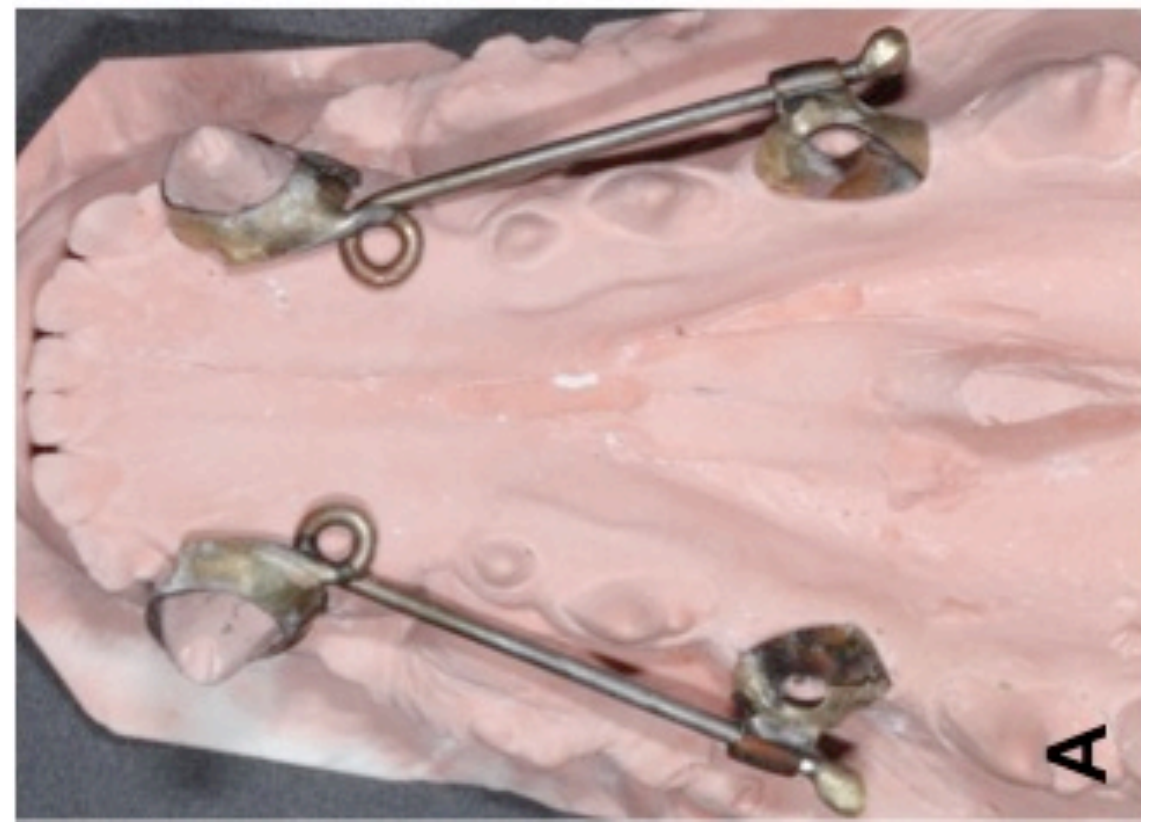

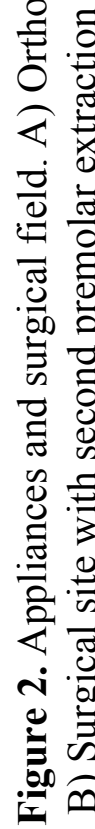




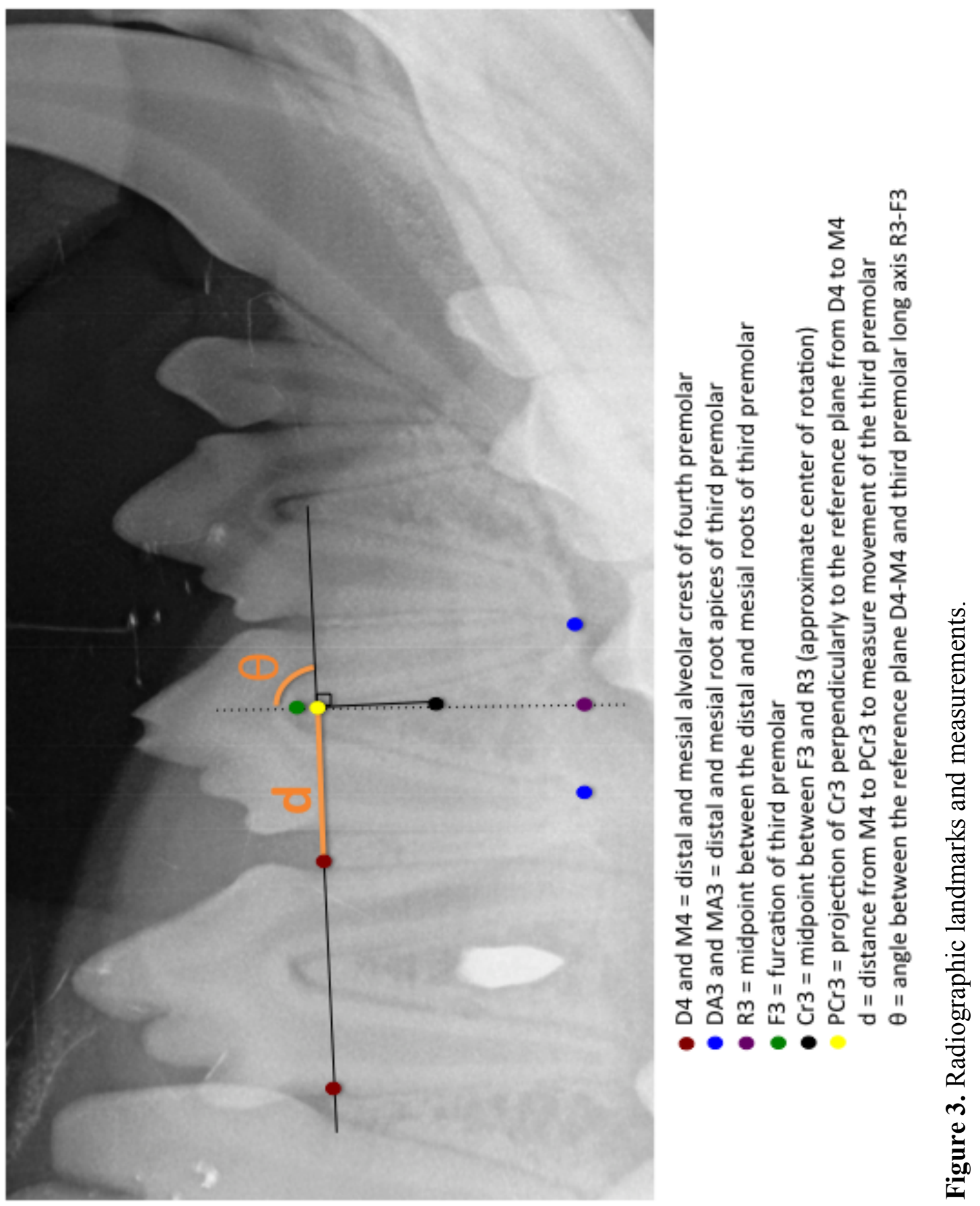




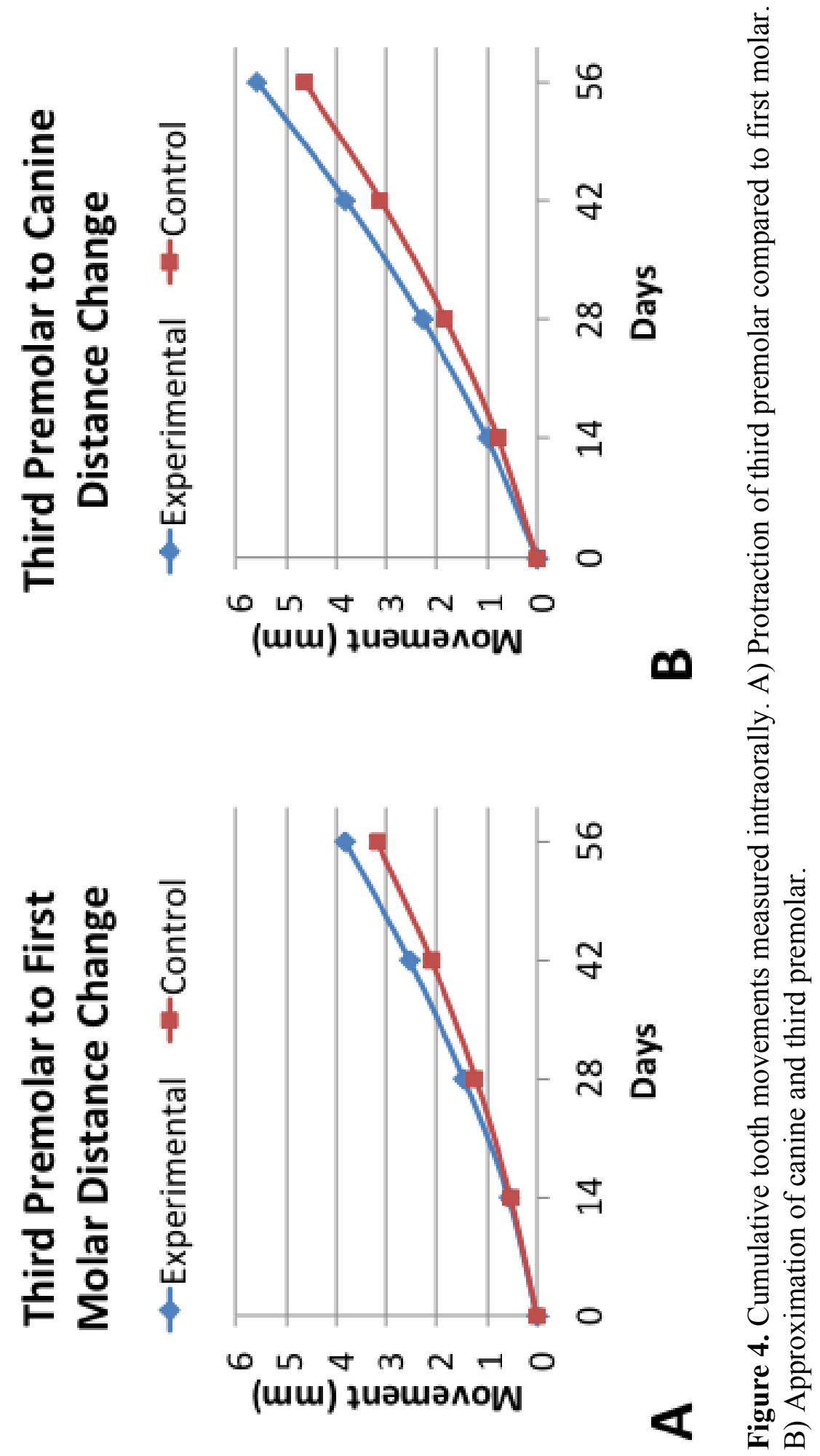




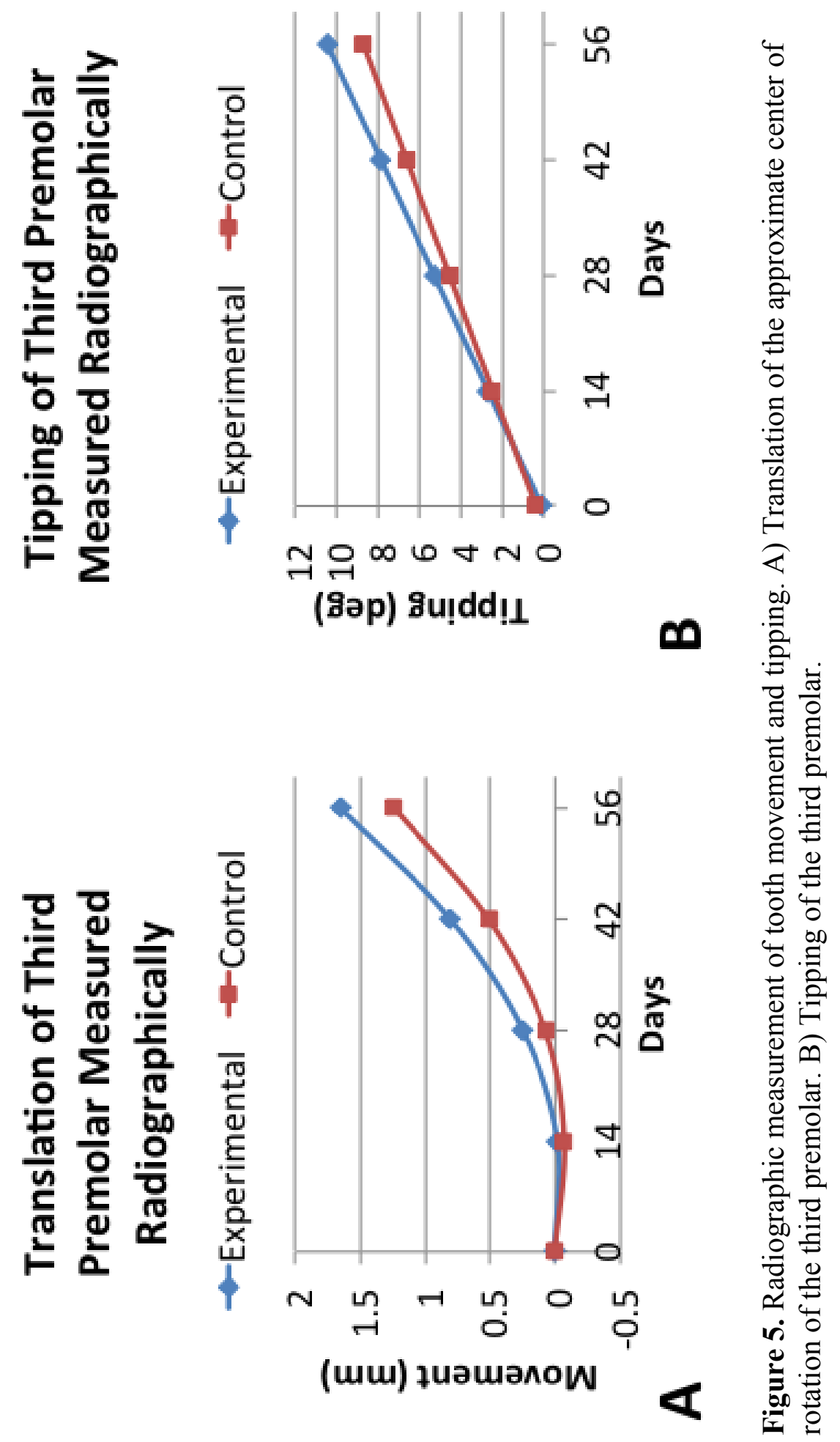




\section{Buccal}

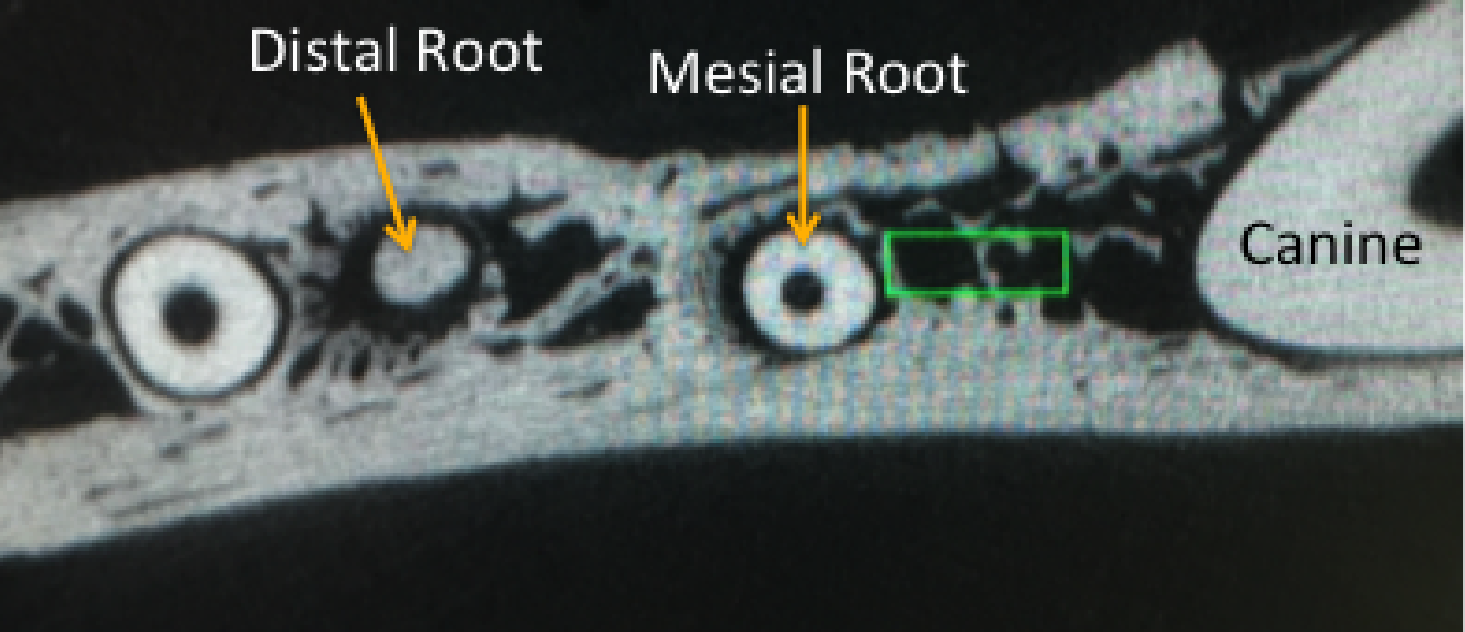

\section{Lingual}

Figure 6. Area of medullary bone mesial to the third premolar assessed by microCT. The area measured approximately $1 \mathrm{~mm}$ x $3 \mathrm{~mm}$, represented by the green box. 


\section{APPENDIX B}

TABLES

\begin{tabular}{|c|c|c|c|c|c|}
\hline & \multicolumn{2}{|c|}{ Debonded Appliance } & \multicolumn{2}{c|}{ Detached Spring } & \multirow{2}{*}{ Total } \\
\cline { 2 - 5 } & Control & Experimental & Control & Experimental & \\
\hline Dog A & 0 & 0 & 0 & 0 & 0 \\
Dog B & 1 & 0 & 0 & 0 & 1 \\
Dog C & 0 & 0 & 0 & 0 & 0 \\
Dog D & 1 & 0 & 0 & 0 & 1 \\
Dog E & 0 & 0 & 0 & 0 & 0 \\
Dog F & 2 & 0 & 0 & 1 & 3 \\
Dog G & 0 & 1 & 0 & 0 & 1 \\
\hline Total & 4 & 1 & 0 & 1 & 6 \\
\hline
\end{tabular}

Table 1. Incidences of damaged appliances. 


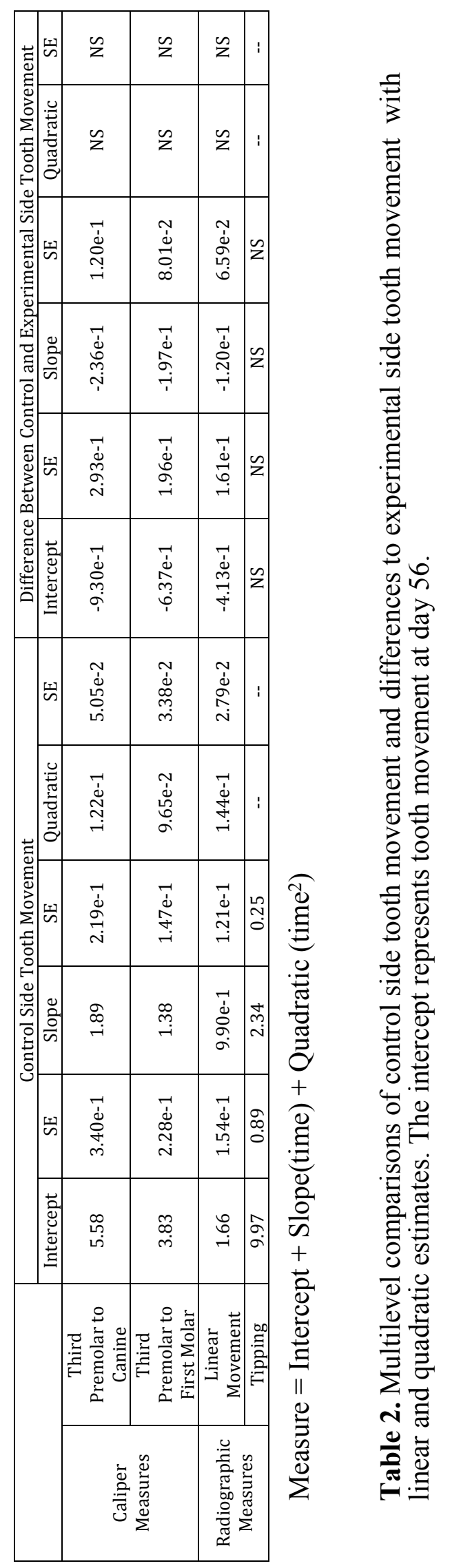




\begin{tabular}{|c|c|c|c|c|c|}
\hline \multirow{2}{*}{} & \multicolumn{2}{|c|}{ Control } & \multicolumn{2}{c|}{ Experimental } & \multirow{2}{*}{ p value } \\
\cline { 2 - 5 } & Mean & SD & Mean & SD & \\
\hline Bone Volume Fraction & 0.24 & 0.10 & 0.22 & 0.10 & 0.02 \\
\hline Apparent Density & 241.67 & 76.85 & 220.03 & 69.90 & 0.03 \\
\hline Material Density & 794.12 & 54.01 & 770.93 & 29.59 & 0.20 \\
\hline Trabecular Number & 1.83 & 0.31 & 2.01 & 0.61 & 0.20 \\
\hline Trabecular Thickness & 0.26 & 0.09 & 0.21 & 0.04 & 0.09 \\
\hline Trabecular Spacing & 0.58 & 0.09 & 0.57 & 0.17 & 0.25 \\
\hline
\end{tabular}

Table 3. Bone volume ratios and bone densities for medullary bone mesial to the third premolar. 